\title{
Flexible energy conversion and storage via high-temperature gas-phase reactions: The piston engine as a polygeneration reactor
}

\author{
Burak Atakan $^{\text {a,* }}$, Sebastian A. Kaiser ${ }^{\text {, }}$, Jürgen Herzler ${ }^{a}$, Sylvia Porras ${ }^{\mathrm{b}}$, Kai Banke ${ }^{\mathrm{a}}$, \\ Olaf Deutschmann $^{\mathrm{c}}$, Tina Kasper ${ }^{\mathrm{a}}$, Mustapha Fikri ${ }^{\mathrm{a}}$, Robert Schieß1 ${ }^{\mathrm{b}}$, Dominik Schröder ${ }^{\mathrm{a}}$, \\ Charlotte Rudolph $^{\mathrm{a}}$, Dennis Kaczmarek ${ }^{\mathrm{a}}$, Hendrik Gossler ${ }^{\mathrm{c}}$, Simon Drost ${ }^{\mathrm{b}}$, Viatcheslav Bykov ${ }^{\mathrm{b}}$, \\ Ulrich Maas ${ }^{\mathrm{b}}$, Christof Schulz ${ }^{\mathrm{a}}$ \\ ${ }^{a}$ IVG, Institute for Combustion and Gas Dynamics, Universität Duisburg-Essen, 47057, Duisburg, Germany \\ ${ }^{\mathrm{b}}$ Institute of Technical Thermodynamics, Karlsruhe Institute of Technology (KIT), 76131, Karlsruhe, Germany \\ ${ }^{\mathrm{c}}$ Institute for Chemical Technology and Polymer Chemistry, Karlsruhe Institute of Technology (KIT), 76131, Karlsruhe, Germany
}

\section{A R T I C L E I N F O}

\section{Keywords:}

Polygeneration

Engine

HCCI

Kinetics

Thermodynamics

Methane

\begin{abstract}
A B S T R A C T
Piston engines are typically considered devices converting chemical energy into mechanical power via internal combustion. But more generally, their ability to provide high-pressure and high-temperature conditions for a limited time means they can be used as chemical reactors where reactions are initiated by compression heating and subsequently quenched by gas expansion. Thus, piston engines could be "polygeneration" reactors that can flexibly change from power generation to chemical synthesis, and even to chemical-energy storage. This may help mitigating one of the main challenges of future energy systems - accommodating fluctuations in electricity supply and demand. Investments in devices for grid stabilization could be more economical if they have a second use.

This paper presents a systematic approach to polygeneration9 in piston engines, combining thermodynamics, kinetics, numerical optimization, engineering, and thermo-economics. A focus is on the fuel-rich conversion of methane as a fuel that is considered important for the foreseeable future. Starting from thermodynamic theory and kinetic modeling, promising systems are selected. Mathematical optimization and an array of experimental kinetic investigations are used for model improvement and development. To evaluate technical feasibility, experiments are then performed in both a single-stroke rapid compression machine and a reciprocating engine. In both cases, chemical conversion is initiated by homogeneous-charge compression-ignition. A thermodynamic and thermo-economic assessment of the results is positive. Examples that illustrate how the piston engine can be used in polygeneration processes to convert methane to higher-value chemicals or to take up carbon dioxide are presented. Open issues for future research are addressed.
\end{abstract}

\section{Introduction}

In the transformation of the energy system towards sustainable sources of primary energy, like wind, solar, and biomass, several approaches for the conversion and storage of energy are discussed. A large part of the primary energy from such sources will be available in the form of electricity, and large fluctuations in generation and demand on various timescales will have to be handled. Storing energy in electrochemical devices like batteries seems an obvious solution since it has the advantage of high conversion efficiencies. However, this is counterbalanced by the low volumetric and specific energy densities and the high costs per unit stored energy. Thus, energy storage in batteries will remain limited in capacity. For the large-scale energy storage that is required to bridge longer time spans and to enable long-distance mobility, chemical storage in bulk materials is important.

A considerable amount of the sustainable primary energy is expected to come from biogenic sources, including biogas consisting to a large part of methane. In addition, in several $\mathrm{CO}_{2}$-reduction scenarios, it appears that natural gas will continue to be converted at least on an extended intermediate time scale, until the $\mathrm{CO}_{2}$ reduction surpasses $90 \%$ [1]. Currently, $95 \%$ of the global use of methane (or natural gas) is for energy conversion, while only about $5 \%$ are used in chemical industry, mainly via conversion to synthesis gas $\left(\mathrm{H}_{2} / \mathrm{CO}\right.$ mixtures, also

\footnotetext{
* Corresponding author.

E-mail address: burak.atakan@uni-due.de (B. Atakan).
} 

Symbols and abbreviations
Quantity Symbol Unit
Temperature $T \mathrm{~K}$
Pressure $p$ Pa or bar
Volume $V \mathrm{~m}^{3}$
Mole fraction $x 1$
Mass fraction $w 1$
Molar amount $n$ mol
Concentration $c \mathrm{~mol} / \mathrm{m}^{3}$
Yield of product $i$ (actual $n_{i} / \max$. possible $n_{i}$ ) $\quad Y_{\mathrm{i}} 1$
Conversion of reactant $k\left(n_{k}^{0}-n_{k}\right) / n_{k}^{0}$ (superscript ,0“: initial mixture) $X_{\mathrm{k}} 1$
Selectivity $Y_{\mathrm{i}} / X_{\mathrm{k}} \quad S_{\mathrm{ik}} 1$
Carbon yield (carbon in $i$ /total carbon in initial mixture) $Y_{\mathrm{C}} 1$
Compression ratio $\varepsilon 1$
Fuel/air equivalence ratio $\phi 1$
Efficiency $\eta 1$
Power $P \mathrm{~W}$
Enthalpy $H \mathrm{~J}$
Gibbs enthalpy $G \mathrm{~J}$
Exergy $E \mathrm{~J}$
Entropy $S \mathrm{~J} / \mathrm{K}$
Work $W \mathrm{~J}$
Heat $Q \mathrm{~J}$
Ignition delay time IDT $s$
Indicated mean effective pressure IMEP Pa or bar
Pressure rise rate $\mathrm{PRR} \mathrm{Pa} / \mathrm{s}$
Crank angle $\mathrm{CA}^{\circ}$

abbreviated "syngas") and then towards different useful chemicals like alcohols, alkenes, and others. Syngas production can go along different paths, such as steam reforming or partial oxidation. Exergetic efficiencies near $63 \%$ are reached for these processes [2]. The energetic use of methane takes place in combustion processes, either in stand-alone piston engines and gas turbines, or in combined-cycle power plants. The exergetic efficiency of the latter is good $(>60 \%)$, while the efficiencies of the former two are much lower, often below 35\%. One may ask whether a combined process producing work, heat, and useful chemicals may have a better efficiency than two separate processes. For several polygeneration systems this advantage has been demonstrated. However, the literature examples mostly concern otherwise unchanged processes that are combined into polygeneration systems by coupling heat flows or by re-using otherwise unused exhaust streams, e.g. Ref. [3-7]. Additionally, such a polygeneration process that can be shifted between different input and output targets could dampen the fluctuating availability and demand of electrical energy.

The combustion community traditionally aims to describe, predict, and design combustion systems in which the chemical reactions are coupled to various, often turbulent flow fields to achieve high conversion efficiencies with low amounts of pollutant formation. Since mechanical work (or sometimes kinetic energy, as in aerospace engines) is the typical target output of such processes, stoichiometric or fuel-lean combustion has been in the center of interest. Complex chemical reaction mechanisms were developed to predict the pollutant formation and thus control the processes to minimize pollutant concentrations in the exhaust gases. The main pollutants addressed are nitric oxides, particles including soot, and unburned or partially oxidized hydrocarbons.

Such partially oxidized species are pollutants when exhausted to the environment but are actually useful when produced in the chemical industry. For them to be synthesized in high-temperature reactions, the equivalence ratio must be fuel-rich, which is unusual for traditional combustion. The question then is if and how the approaches and mechanisms used for traditional combustion can also be employed or extended towards fuel-rich combustion to understand and create operating conditions in piston engines that maximize the output of useful chemicals. Several issues arise. One of them is the feasibility of initiating reactions on a time scale that is characteristic for typical engine processes. Another one is the competition of the formation of the wanted small (oxygenated) hydrocarbon species with the formation of unwanted by-products like soot. Other important questions include the challenges of gas separation and the overall thermodynamics and economics.

The compression-expansion process in an internal combustion (IC) piston engine has direct influence on the reacting gas mixture. Compression leads to a temperature rise initiating high-temperature reactions, while the expansion stroke leads to a temperature decrease that can be useful to slow down (freeze) the reactions and prevent the conversion of valuable metastable intermediates, so that they can be harvested from the product stream. One may ask how to choose a time-temperature profile that leads to high yields of wanted products and reduces the formation of unwanted products. Some of the primary issues are related to the potential products that can be expected from thermodynamics and chemical reaction kinetics: Besides syngas, is it possible to produce significant amounts of unsaturated or partially oxidized hydrocarbons? Can the formation of large amounts of soot be prevented? Is the flame-speed-controlled spark-ignition process preferable or a kinetically controlled homogeneous-charge compression-ignition (HCCI) process, where the premixed mixture is ignited due to compression? Methane and natural gas are comparably inert, and high temperatures are needed for ignition. This property may lead to problems in the HCCI process. Ignition-enhancing additives might be of interest to increase reaction rates already at moderate temperatures.

Methane reforming in IC engines has been investigated in the past. Since a recent extensive review on fuel reforming in IC engines by Tartakovsky and Steintuch is available [8], only a few papers are mentioned here. Very recently Eyal and Tartakovsky analyzed the entropy production in HCCI engines with external reforming and found efficiencies improved by 7-9\% [9]. In a dual-fuel approach with thermochemical recovery, Chuahy and Kokjohn improved the second-law efficiency by $20 \%$ [10]. Reforming in HCCI engines was also investigated with the respect to reducing the pressure rise rate, but turned out to be of minor importance [11]. But fuel reforming with the heat from the exhaust gas may help in HCCI control [12]. However, in these works the fuel was reformed outside of the engine itself, and the main purpose of the overall process was to produce mechanical power.

Also true in-cylinder reforming has been investigated. Already in 1956, Szeszich produced syngas in a spark-ignition (SI) engine via partial oxidation of methane/oxygen mixtures [13]. Equivalence ratios between $\varphi=2.58$ and 2.86 yielded up to 95 vol\% syngas in the dry exhaust (product) gas. McMillian and Lawson investigated the combustion of fuel-rich natural-gas mixtures in SI engines in experiment and simulation [14]. At a compression ratio of $\varepsilon=13.3$ and equivalence ratios from $\varphi=1.3$ to $1.6, \mathrm{H}_{2}$ fractions of up to $11 \mathrm{vol} \%$ in the dry exhaust were found. Lim et al. [15] preheated the intake mixture up to $723 \mathrm{~K}$ to achieve stable SI operation at equivalence ratios between 1.8 and 2.8. at $\varepsilon=13.8$. They added $\mathrm{H}_{2}$ and $\mathrm{C}_{2} \mathrm{H}_{6}$ to the mixture and found that especially $\mathrm{H}_{2}$ addition reduced the required intake temperature. Karim et al. investigated partial oxidation in a Diesel engine. Fuel-rich mixtures of methane and oxygen-enriched air were ignited by a very short diesel fuel injection [16]. This enabled operation up to about $\varphi=$ 2.4 and yielded a maximum syngas fraction of $80 \%$ in the dry exhaust. While the chemical conversion was investigated in some depth, the thermodynamic and economic assessment is often lacking, even though 
it is crucial for large-scale and wide-spread implementation.

Reaction mechanisms for the fuel-rich regime exist, but generally they are not well-validated for high equivalence ratios. Therefore, their evaluation and improvement are necessary, which includes validation experiments with respect to ignition kinetics and product species predictions. Several mechanism describing the oxidation of DME or $\mathrm{CH}_{4} /$ DME mixtures are published, e.g. Fischer et al. (79 species/683 reactions, up to C2-species) [17], Zhao et al. (55 species/290 reactions, up to C2-species) [18], Prince and Williams (63 species/284 reactions, up to C4-species) [19], Burke et al. (113 species/710 reactions, up to C3-species) [20], ARAMCOMech 2.0 (493 species/2716 reactions, up to benzene) [21], ARAMCOMech 3.0 (581 species/3037 reactions, up to C4 and $\mathrm{PAH}$ ) [22]. Our own mechanism, "PolyMech", comprises 83 species and 558 reactions up to benzene. To describe the oxidation and product formation at very fuel-rich conditions, a mechanism must contain benzene, which was identified as one of the main products at $\varphi=10$ in high-pressure shock-tube experiments [23]. Other than PolyMech, only ARAMCOMech 2.0 [21] and ARAMCOMech 3.0 [22] fulfill this requirement, but the former is much smaller than the latter two, making it much more suitable for complex simulations and optimizations.

It is imaginable that polygeneration processes can even be used for chemical storage of mechanical work in endothermal and endergonic processes. That may involve even more unusual thermo-chemical states. Experiments for the development and improvements of reaction mechanism can take place in flow reactors, shock tubes, or rapid-compression machines (RCM), the latter being already a first step towards a reciprocating piston engine.

While conditions are easily varied in an RCM, there are more complexities in real engines. Intake preheating or variations in compression ratio and reactant compositions may entail significant hardware modification. In particular in HCCI mode, excessive cycle-to-cycle variations and high pressure rise rates limit useful engine operation. Therefore, engine experiments are crucial for identifying practical issues and determining realistic efficiencies and yields. The number of process parameters can become quite large, i.e., intake temperature and pressure, compression ratio, equivalence ratio, engine speed, additive concentrations, etc. Here, mathematical optimization, even with less-thanperfect reaction mechanisms, can help the experimentalists to choose promising sets of conditions. For this optimization, but also for future multi-dimensional modeling of complex turbulent flows with fuel-rich chemistry, a reduction of the newly developed and optimized reaction mechanisms is necessary.

In addition to the processes in the IC engine itself, a polygeneration process may require upstream conditioning of the reactants, like preheating, compression, or mixing, and then downstream separation and after-treatment of the products. The associated thermodynamic losses (or gains) cannot be neglected in an accurate evaluation of the overall efficiency. Beyond thermodynamics, the economics of the process need to be assessed, again in comparison with separate processes with the same products. Since large uncertainties are present in such an analysis, a global sensitivity analysis helps finding the most important parameters and possible price ranges for the products, and their uncertainty.

This overview indicates that the cooperation of several scientific disciplines is required, including contributions from combustion science. In the following, the reasoning, procedures, and most important results will be presented from such an inter-disciplinary collaboration. The article follows the collaborative research procedure. It is structured along the initial (a priori) selection and evaluation of promising parameters and processes, followed by the discussion of kinetics studies and model development and reduction. The implementation in an RCM and a reciprocating IC engine follows, before the thermodynamics and thermo-economics of the complete process including gas separation are discussed for a selected example. In all parts, the main example process is partial oxidation with positive work output from the system, but energy storage systems, where work is transferred into the system, are also considered.

\section{Thermodynamics and kinetics assessment - a priori}

\subsection{Thermodynamics}

The combustion of methane (or any other hydrocarbon) at an equivalence ratio $\phi=1$ can be complete with the products of lowest chemical potential formed, water and carbon dioxide:

$\mathrm{CH}_{4}+2 \mathrm{O}_{2}=\mathrm{CO}_{2}+2 \mathrm{H}_{2} \mathrm{O}$

This reaction is strongly exothermal and exergonic, with Gibbs energies $\left(G_{r}\right)$ and enthalpies $\left(H_{r}\right)$ of about $-800 \mathrm{~kJ} / \mathrm{mol}$, as seen in the first row of Table 1. If the amount of $\mathrm{O}_{2}$ is reduced, as seen in the next lines of the table, the reaction becomes less exothermal and exergonic, but it remains exergonic even at an equivalence ratio $\phi=4$ (row/reaction (3)). The change in Gibbs energy gives the amount of work which could potentially be transferred from the system. Thus, even for reactions carried out at $\phi=2$ (row/reaction (2)), significant work $\left(-315 \mathrm{~kJ} / \mathrm{mol}^{1}\right)$ could be transferred from the system along a reversible path, while syngas with an $\mathrm{H}_{2} / \mathrm{CO}$ ratio of unity is produced.

Instead of evaluating the material and energetic outputs separately, a holistic concept is preferable. From thermodynamics, the concept of exergy (or available energy) is available for that purpose. Exergy is conserved in reversible processes, while it is (in part) destroyed in irreversible processes. Lean combustion generally leads to much exergy destruction, limiting the efficiency of such processes. The exergetic analysis of fuel-rich combustion in gas-turbine cycles [24] shows that the exergy is conserved to more than $85 \%$ at equivalence ratios above 2 , while it was below $70 \%$ in the fuel-lean regime. Thus, fuel-rich combustion with work transfer from the system seems to be promising. As opposed to that previous work, the current investigation focuses on piston engines rather than gas turbines, mostly because the experimental effort is much lower, but that preliminary conclusion from theory should still hold.

Table 1 also shows that if $\mathrm{O}_{2}$ is not added (row/reaction 4), endergonic and endothermal conversion can take place, e.g., to form acetylene $\left(\mathrm{C}_{2} \mathrm{H}_{2}\right)$. This would be a possible way to store mechanical energy by increasing the Gibbs energy of the gas mixture. The products could either be used later in combustion reactions making use of their increased combustion enthalpy, or preferably, they could be used directly in the chemical industry. One could even combine the endothermal-endergonic conversion of methane with the carbon dioxide conversion to form syngas via dry reforming (row 5). This could be one step within a carbon capture and utilization (CCU) processes. Again, the syngas produced this way could be burned or used, e.g., in a FischerTropsch synthesis.

\subsection{Kinetics}

Although the thermodynamic analysis promises small exergy losses if methane is converted in a polygeneration process, such a process may not be technically feasible because of the low reactivity of methane. For HCCI, ignition of the gas mixture must take place as a result of the temperature rise after compression and initiate the radical chemistry responsible for both pyrolytic and oxidative processes. Ignition delay times (IDTs) in a piston engine mainly depend on the initial temperature of the gas mixture, the compression ratio, and the heat capacity ratio. The available time is related to the engine speed. At speeds between 600 and $3000 \mathrm{rpm}$ (revolutions per minute), the entire cycle takes place on a time scale of some tens of milliseconds. Maybe one-tenth of the cycle is available if ignition and the bulk of the reactions are to complete near or shortly after top dead center (TDC), which is thermodynamically most

\footnotetext{
1 The so-called "European" thermodynamics sign convention is used throughout this work. Energy flows into the system are positive, out of it negative.
} 
Table 1

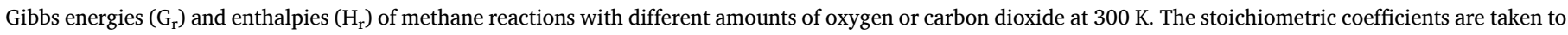

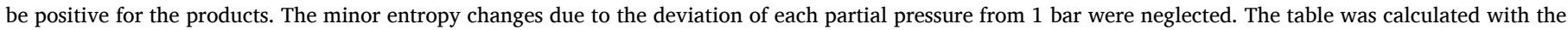
thermodynamics data from the NASA tables for $300 \mathrm{~K}$ and 1 bar [25].

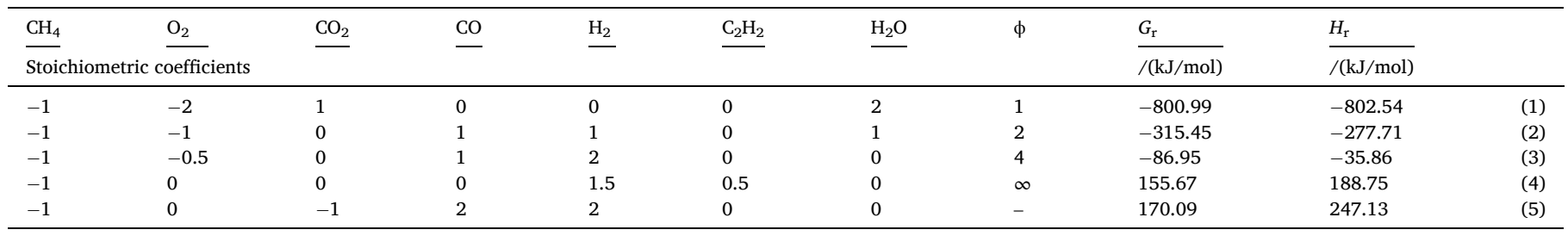

favorable. Methane ignition generally has IDTs of less than $1 \mathrm{~ms}$ for temperatures above $1300 \mathrm{~K}$. The heat capacity ratio increases with the equivalence ratio, reducing the temperature reached at TDC. This can be counterbalanced by higher intake temperatures or higher compression ratios. If conventional IC engines are to be used, the intake temperature should remain below $430-470 \mathrm{~K}$, although some researchers modified the engine such that $753 \mathrm{~K}$ were possible [15]. Typical compression ratios $\varepsilon=V_{\max } / V_{\min }$ are in the range of 8-25.

Additives that ignite at lower temperatures can reduce the required intake temperature. Several additives are possible candidates as ignition enhancers for methane, e.g., n-heptane [26], dimethyl ether (DME) [23], or other ethers [27-30]. Hegner et al. [31] performed a simulation-based pre-selection of process parameters and additives. Using a detailed chemical mechanism, but without soot formation, the engine cylinder was modeled as a homogeneous adiabatic single-zone reactor. A series of consecutive strokes was simulated, including the effect of mixing the remaining reacted gas mixture with the unreacted fresh gases at the start of each compression. Selecting a base case with an engine speed of 3000 and a compression ratio of 16.5 with methane and air as reactants, the influence of several parameters on the required intake temperature and on several output parameters was investigated. At an equivalence ratio of 2 , an intake temperature of $635 \mathrm{~K}$ was needed to ignite methane. Increasing the compression ratio to 22 reduced that to $555 \mathrm{~K}$. Reducing the engine speed to $600 / \mathrm{min}$ instead had a comparable effect $(560 \mathrm{~K})$, while replacing $10 \mathrm{~mol}-\%$ of the methane by DME reduced the intake temperature to $455 \mathrm{~K}$. The work output per cycle (but not per mass of fuel) did not vary much when increasing the equivalence ratio from 0.5 to 2 , but the exergetic efficiency of this idealized system increased by $12 \%$-points. Thus, DME addition appears to be a promising approach for enabling an HCCI polygeneration process and its influence on ignition kinetics and engine operation was investigated in more detail, as discussed below.

The residual gas from the previous cycle - depending on the compression ratio 5-10 vol\% of the fresh charge - influences the current cycle. Since this gas has a higher temperature than the intake, it is expected to reduce the required intake temperature. Fig. 1 shows a typical example of a crank-angle resolved simulation result for methane conversion at an equivalence ratio of 2, calculated with the mechanism of Burke [20]. The simulation is converged on a cycle basis, i. e, each cycle does not differ from the previous one. The intake temperature needed for ignition of pure methane at an engine speed of $600 \mathrm{rpm}$ and $\varepsilon=18$ is $428 \mathrm{~K}$, while it is $560 \mathrm{~K}$ if the residual gas is excluded. From the figure it is seen that relatively large fractions of $\mathrm{H}_{2}$ and $\mathrm{CO}$ are formed at $11^{\circ} \mathrm{CA}$ after top dead center (aTDC). These species also survive until the end of the cycle. This is different for ethylene and acetylene. Both are produced in low concentrations between 10 and $11^{\circ} \mathrm{CA}$, and both are converted quickly at these conditions.

The final mole fractions near $180^{\circ} \mathrm{CA}$ describe the potential composition of the product gas of a polygeneration process. They are shown in Fig. 2 as a function of equivalence ratio for methane as fuel with a compression ratio of 18 and an engine speed of $600 \mathrm{rpm} . \mathrm{H}_{2}$ and $\mathrm{CO}$ are predicted to be produced in considerable mole fractions, generally with an $\mathrm{H}_{2} / \mathrm{CO}$ ratio above 1 . Unsaturated hydrocarbons like

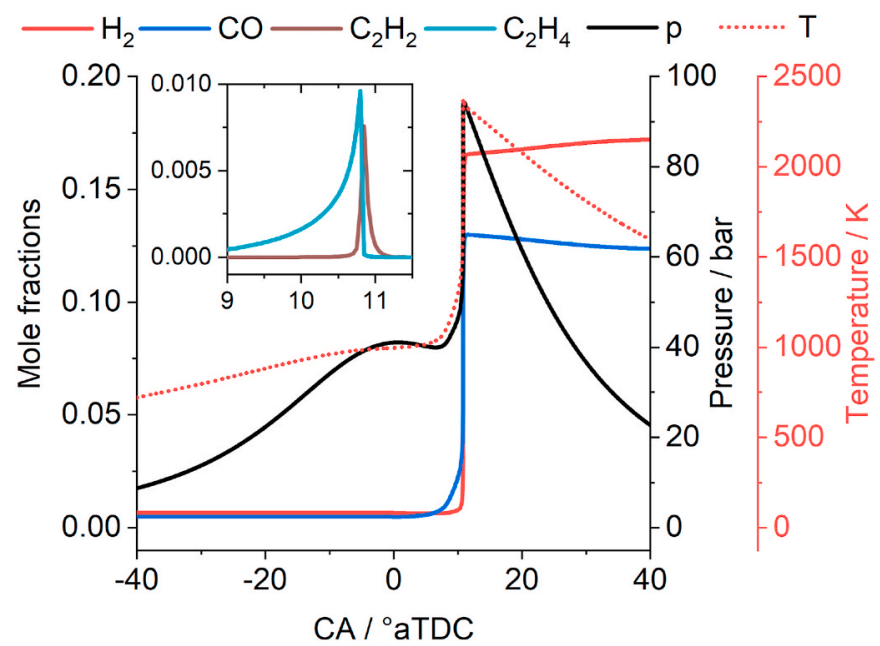

Fig. 1. Crank-angle resolved simulation of methane conversion (without additive) for an equivalence ratio of $\phi=2$, an engine speed $N=600 \mathrm{rpm}$, a compression ratio $\varepsilon=18$ and an intake temperature of $428 \mathrm{~K}$.

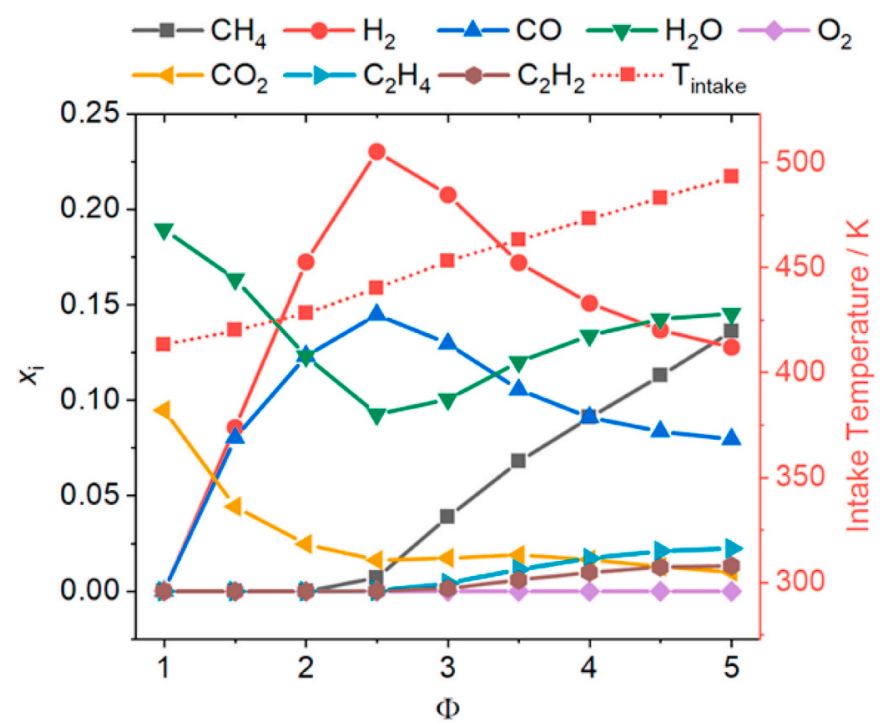

Fig. 2. Major product species as a function of equivalence ratio $(N=600 \mathrm{rpm}$, $\varepsilon=18$ ) on the left axis. The intake temperature needed for ignition is plotted on the right axis.

acetylene and ethylene are predicted to be formed at lower concentrations at very fuel-rich conditions. Since air is the oxidizer here, large fractions of $\mathrm{N}_{2}$ are present in the mixture, thus the product mole fractions are in part limited by the inert-gas mole fraction. The separation of the product-gas mixture will need to be addressed later. It is also seen that at these conditions the methane conversion is incomplete at higher 
equivalence ratios.

\subsection{Product yield optimization}

Ethylene is an important industrial chemical and the precursor for polyethylene. A catalytic polygeneration process for its production has been mathematically optimized [7]. It is interesting to explore a potentially simpler non-catalytic process in an engine. However, the mole fractions of ethylene shown in the previous section are in the range of $0-2.5 \%$ and are thus relatively low. Numerical optimization was employed to potentially find operating conditions leading to higher product yields. For ethylene production, a suitable objective function to be maximized in such optimization is the mole fraction of ethylene at the end of the expansion stroke. The optimization variables here are the engine speed $N$, and the fresh gas composition $n\left(t_{0}\right)$, where the considered reactants are $\mathrm{CH}_{4}, \mathrm{DME}, \mathrm{O}_{2}$, and $\mathrm{N}_{2}$. The initial temperature $T_{0}$ is kept constant for each optimization run. Two linear constraints are formulated: One to ensure that the initial pressure $p_{0}$ is equal to $1.0 \mathrm{bar}$, by using the ideal gas equation. The second linear constraint ensures that the $\mathrm{N}_{2} / \mathrm{O}_{2}$ ratio corresponds to that of air. An inequality constraint is in place to make sure that the amount of additive is at most $10 \%$ of the fuel. This avoids potential situations in which the additive is the main fuel component instead of methane. Bounds for the engine speed were set to $60-6000 \mathrm{rpm}$. As for the work discussed in the section above, a simple single-zone model was used [32] with the chemical mechanism "PolyMech" [23] including detailed chemistry without soot, as will be discussed in Section 3.1.

Fig. 3 shows the results of the optimization for $\mathrm{C}_{2} \mathrm{H}_{4}$ as a function of the fresh gas temperature. The bottom graph shows the optimal conditions at a given temperature that lead to the yields $Y$ and conversion $X$ (i. e., the outcome) shown in the top graph. The top graph also shows the conversion of methane on the right axis at the corresponding conditions shown in the bottom. DME is fully converted at all shown conditions; for clarity, this is not shown in the figure. Although the $\mathrm{C}_{2} \mathrm{H}_{4}$ mole fraction at the end of the expansion stroke was maximized in the optimization, the top graph shows the yield (left axis) as this represents a better metric to assess the outcome of the process. Except for $\mathrm{H}_{2}$, the yield was calculated on the basis of $\mathrm{C}$ atoms according to the formula

$$
Y_{i, j}(t)=\frac{a_{j, i} n_{i}(t)-a_{j, i} n_{i}\left(t_{0}\right)}{\sum_{\ell \in I}\left(a_{j, \ell} n_{\ell}\left(t_{0}\right)\right)_{\ell \neq i}}
$$

where $a_{j, i}$ is the number of atoms of type $j$ (i.e., element) in species $i, I$ denotes the set of species indices, and $n$ is the amount of substance. Equation (2) effectively states how many of the initially available atoms of type $j$ (given by the sum in the denominator) are bound in product $i$.

The engine speed (optimization variable) is plotted directly, while the gas composition is represented by the equivalence ratio $\varphi$ and the molar fraction of DME in the fuel. For example, at $T_{0}=600 \mathrm{~K}$, the optimal remaining operating parameters are $\phi=3.5$, a fuel composition of $4.7 \%$ DME and $95.3 \% \mathrm{CH}_{4}$, and an engine speed of $6000 \mathrm{rpm}$. Operating the engine with those parameters is predicted to result in a $\mathrm{C}_{2} \mathrm{H}_{4}$ yield of $19.8 \%$.

In the considered temperature range, the predicted $\mathrm{C}_{2} \mathrm{H}_{4}$ yields are between $15 \%$ at $400 \mathrm{~K}$ and over $21 \%$ at $750 \mathrm{~K}$. At intake temperatures above about $520 \mathrm{~K}$, the optimum engine speed is always at the maximum set limit of $6000 \mathrm{rpm}$, indicating that higher yields could be obtained at higher speeds. Optimum equivalence ratios are between 2.8 at the lowest temperature and 4.2 at the highest. A similar relation between temperature and equivalence ratio was observed for the $\mathrm{H}_{2}$ optimization ( $\phi=2.5-3)$. High temperatures permit richer mixtures, i.e., higher $\phi$ values. The predicted DME content in the fuel spans the complete range of permissible values. At lower intake temperatures, the optimization predicts a DME content of $10 \%$, corresponding to the set bound. This value decreases almost linearly to nearly $0 \%$ at $725 \mathrm{~K}$. Over the entire range of considered inlet temperatures, DME was fully converted (not shown in the figure), whereas $\mathrm{CH}_{4}$ showed conversions of approx. $80 \%$.

Fig. 3 also shows the yields of other species as dashed lines. It can be seen that although the optimization was carried out for $\mathrm{C}_{2} \mathrm{H}_{4}$, other valuable species are also produced with significant yields. $\mathrm{H}_{2}$ yields of around $40 \%, \mathrm{C}_{6} \mathrm{H}_{6}$ yields of $8-10 \%$, but also small fractions of $\mathrm{C}_{2} \mathrm{H}_{2}$ (yields of $0.7-3.1 \%$ ) were obtained. A production of formaldehyde and methanol was not predicted under these conditions. Such optimizations can also be carried out for other valuable chemicals. Since most of them are not stable at high temperatures, the optimized parameters will lead probably to high-speed engine operation.

The results and reasoning so far rely on theory and on models that were in general not developed for such fuel-rich conditions. Thus, the

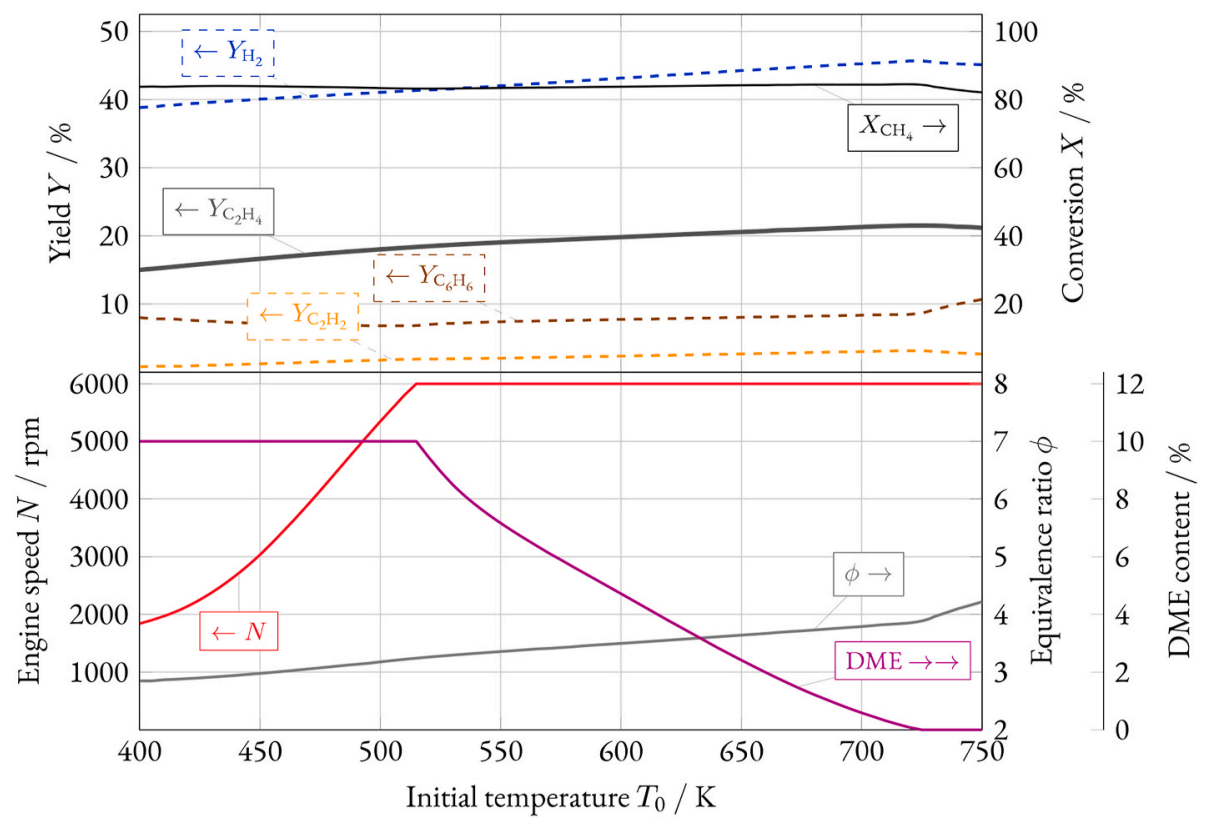

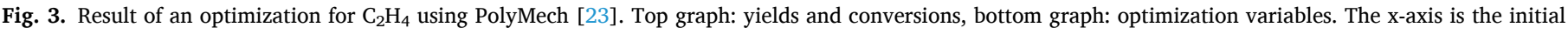
temperature $T_{0}$ that was held constant for each optimization. 
development of validated models using kinetics experiments is discussed next.

\section{Kinetics: model development and experiments}

Generally, kinetic models in combustion are optimized to predict ignition delay times and flame speeds correctly, while the prediction of product species is of minor importance, except when pollutants are addressed. Much work has been published for fuel-lean to slightly fuelrich combustion, but not for higher equivalence ratios. Many mechanistic investigations were carried out at reduced or ambient pressure, while in engines, conditions between near-ambient and pressures of more than 30 bar prevail. In order to assess the predictions of established models, well-characterized kinetics experiments are needed. For example, the existing models (e.g., [20,33]) predict a strong influence of additives like DME or n-heptane on the methane conversion at lower temperatures. A question is whether some of the additives are more effective than others, also the interaction between additive and methane is important, because it is not the goal to convert only the additive. These questions were addressed in experiments in shock tubes, flow reactors, and a rapid-compression machine (RCM). Shock tubes are well suited to study IDTs and reactions at intermediate and high temperatures and short times, while the residence times in RCMs and flow reactors are generally longer and the temperatures lower. Compared to shock tubes and RCMs that require measurements with high time resolution, steady-state flow reactors offer an easier approach to gas-phase diagnostics.

Validation experiments were performed in three different ranges in equivalence ratio: At moderately fuel-rich conditions $(\phi=2)$ with synthesis gas as the main product, at very fuel-rich conditions $(\phi=6-20)$, resulting in the additional formation of higher hydrocarbons, and without oxygen $(\phi=\infty)$, representing methane and natural-gas pyrolysis for energy storage. Additives were mixed with methane to reduce the reaction temperature. Details of the experimental methods are given in Refs. [23,34].

\subsection{Mechanism development and reduction}

\subsubsection{Detailed mechanism}

The chemical mechanism developed here specifically for use in simulations of polygeneration processes is termed "PolyMech" [23]. It is a comparatively small mechanism, based on existing detailed mechanisms describing stoichiometric to slightly fuel-rich $(\phi=1-2)$ combustion and pyrolysis of methane as well as the oxidation of DME/air mixtures. The oxidation model of Heghes et al. [35] was combined with the methane pyrolysis mechanism of Hidaka et al. [36] to characterize the oxidation of methane. Both mechanisms were developed for describing the oxidation and pyrolysis behavior of methane over a wide temperature range. Duplicate reactions contained in both mechanisms were avoided. For better characterization of the product formation at oxidative fuel-rich conditions, reactions describing the pyrolysis and oxidation of acetylene [37], vinylacetylene [38], propyne and allene [39], and the benzene sub-mechanism of Pitz et al. [40] were added. Reactions from the ethanol mechanism of Marinov [41] and the DME mechanism of Zhao et al. [18] are used to model the oxidations and pyrolysis of both additives. For a better description of DME oxidation, further reactions from the mechanism of Burke et al. [20]. were added.

The newly assembled mechanism was then further developed and improved. The first step was the validation of the mechanism with the IDTs and the species concentrations determined in shock tube, RCM, and flow reactor. The comparison of simulation and experiment allows identifying parameter regions where the predictions should be improved. Analyses of the mechanism, including sensitivity and reaction pathway analysis, were carried out to identify the key reactions for a wide range of temperatures and mixture compositions. The reaction rates of some of these reactions were modified based on previous publications, but only within the documented experimental uncertainty range. The resulting mechanism can well predict IDTs and species concentrations for $\mathrm{CH}_{4}$ /additive mixtures over a very wide range in temperature, pressure, and equivalence ratio $(\phi=1-20)$, while the validation was only carried out for fuel-rich conditions. It can also model the pyrolysis of methane and natural gas very well.

\subsubsection{Mechanism reduction}

PolyMech contains 93 species and 575 reactions. This number is moderate in size compared to other mechanisms (e.g., Burke et al., 113 species and 708 reactions [20]) considering that PolyMech describes also product formation of higher hydrocarbons like benzene. But it is still too large for parametric studies with more complex models (e.g., multizone) or CFD simulations that may be needed for the further development of polygeneration processes in reciprocating engines [42]. This motivated the development of reduced-model concepts able to describe combustion processes within an acceptable level of accuracy, but with a significant reduction in computational costs [43]. Therefore, reduced versions of PolyMech were developed.

The reduction method is based on the decomposition of the system into low-dimensional subsystems describing relatively slow and fast dynamics. Timescales and entropy-production analysis are used to decompose the system and to formulate reduced subsystems [44]. Two types of characteristic time scales - global and local - are determined, based on corresponding linear approximations of a vector field of a detailed model of chemical kinetics [45]. The time scales are obtained by using the Jacobian matrix (local analysis) or the global quasi-linearization (GQL) matrix (global analysis) [46]. The identification of low-dimensional sub-systems is carried out by decoupling the relevant timescales. To investigate the relevance of a certain time scale (i.e., mode of chemical reaction process), the concept of relative entropy production is implemented. The entropy produced in each characteristic time scale is calculated using the invariant subspaces of either local or global approximations. The relevance of the time scale is accessed by comparison with the total entropy produced by the system (Fig. 4) [44, $46,47]$. Thereby, sub-groups of timescales describing the dynamics of dormant, relatively slow, and fast processes are identified [44].

Chemical reaction processes can be decomposed into: (i) Fast processes governed by quick relaxation of the system dynamics that in most cases remain stationary or quasi-stationary and in Fig. 4 no significant contribution to entropy production is seen, (ii) very slow (dormant) processes that can be considered as quasi-conserved and again in Fig. 4 no significant contribution to entropy production is seen, and finally (iii) processes with characteristic time scales in between, which describe and govern the progress of chemical reactions, and therefore are the only reactions modes that need to be accounted for. As seen in Fig. 4, the latter contribute strongly to entropy production. The processes with fast and dormant timescales can be approximated by established implicit algebraic relations. Namely, the quasi-steady-state approximation for the fast subsystem and a conservation assumption for the dormant one.

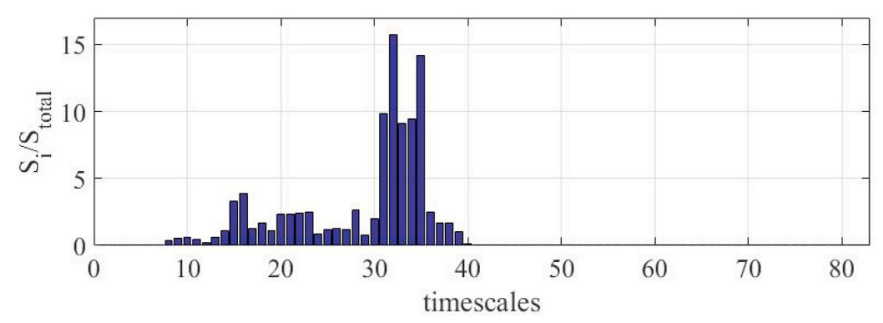

Fig. 4. Contribution of each timescale (mode) to the total entropy production of the system for $\mathrm{CH}_{4} / \mathrm{DME}$ mixtures at $\phi=6, p=10 \mathrm{bar}$, and $T=600 \mathrm{~K}$. On the left are the timescales corresponding to the dormant processes $\left(\lambda_{1}-\lambda_{7}\right)$, in the middle the relevant timescales $\left(\lambda_{8}-\lambda_{39}\right)$, and on the right the fast time scales $\left(\lambda_{40}-\lambda_{83}\right)[46]$. 
Once the fast and dormant reactions are decoupled, the only processes that have to be integrated are those of the relatively slow subsystem [44].

A local characteristic timescale analysis delivers precise information on the development of the system with time but requires higher computational effort because the Jacobian matrix must be calculated and decoupled for each thermo-kinetic state. A global analysis offers a rougher approximation of the timescales, but it nevertheless allows to describe the fast relaxation processes needed to constrain the system dynamics as described above with sufficient accuracy. The GQL matrix also provides a constant approximation for the invariant subspaces. This means, once obtained it can be used for implementations over a wide range of initial conditions $(p, T, \phi)$ [46]. The number of relevant characteristic time-scales corresponds to the dimension of the reduced model [44].

The results of the local analysis can be incorporated in the form of a skeletal mechanism, while the results from the GQL method are implemented as a differential-algebraic system of equations (DAE) or in the form of a skeletal mechanism. Skeletal mechanisms are obtained by further implementation of entropy-production analysis. Key reactions contained in the skeletal mechanism are identified by evaluating the entropy produced by each reaction on each relevant time scale. This process is repeated for several sets of parameters $(p, T, \phi)$, so that the obtained skeletal mechanism will be valid for a wide range of initial conditions.

The detailed version of PolyMech was reduced to two skeletal mechanisms, one from the local analysis and one from the global analysis [44,47]. For a $\mathrm{CH}_{4} / \mathrm{DME}$ mixture, Fig. 5 compares results obtained with the two skeletal mechanisms with predictions with the detailed version of PolyMech. Since almost no difference is observed when the species mole fractions are plotted over the reaction time, Fig. 5 a presents the temperature as a function of mole fractions of other chemical species like $\mathrm{CO}$ and $\mathrm{CH}_{2} \mathrm{O}$. Fig. $5 \mathrm{~b}$ shows that IDTs from the simulations with both reduced models are very similar (the discrepancy is around 1\%). Compared to the detailed mechanism, IDTs obtained with the skeletal mechanism from the local analysis have an average error of $4.5 \%$, while from the global analysis the error is slightly greater (5.4\%). The temporal evolution of the state space represented in Fig. 5a shows that the skeletal mechanisms predict the final (equilibrium) state of the mixture very well, while compared to the detailed model their time traces show discrepancies of up to $3 \%$ for the local analysis and up to $26 \%$ for the global analysis.

With local analysis, a dimension of 32 was found to be sufficient to describe the ignition process with an acceptable accuracy, while with global analysis a dimension of 38 remains. This represents a reduction in dimensionality of about $60 \%$ with respect to the detailed mechanism. Fig. 6 graphically represents the number of reactions and species in the three versions of PolyMech.

A representation of the reduced model as a DAE in implicit form is only possible in the case of the global analysis, in which an optimal GQL matrix is obtained. The GQL matrix is used to find the sub-space of slow processes and to formulate the slow sub-system that needs to be integrated. The integration of the slow sub-system is carried out in HOMREA [48] such that other sub-systems governing fast and dormant processes are approximated automatically by quasi-steady-state and quasi-conservation assumptions. The dimension of the reduced model is in this case equal to the dimension of the slow invariant subspaces of the GQL matrix. For IDTs an error of $1.5 \%$ is obtained. IDTs obtained using the skeletal mechanism and the implicit form of the global analysis are compared in Fig. 7. Good agreement of both results with each other and with the results of the detailed simulation is observed, even though better predictions are obtained using the implicit form of the reduced model.
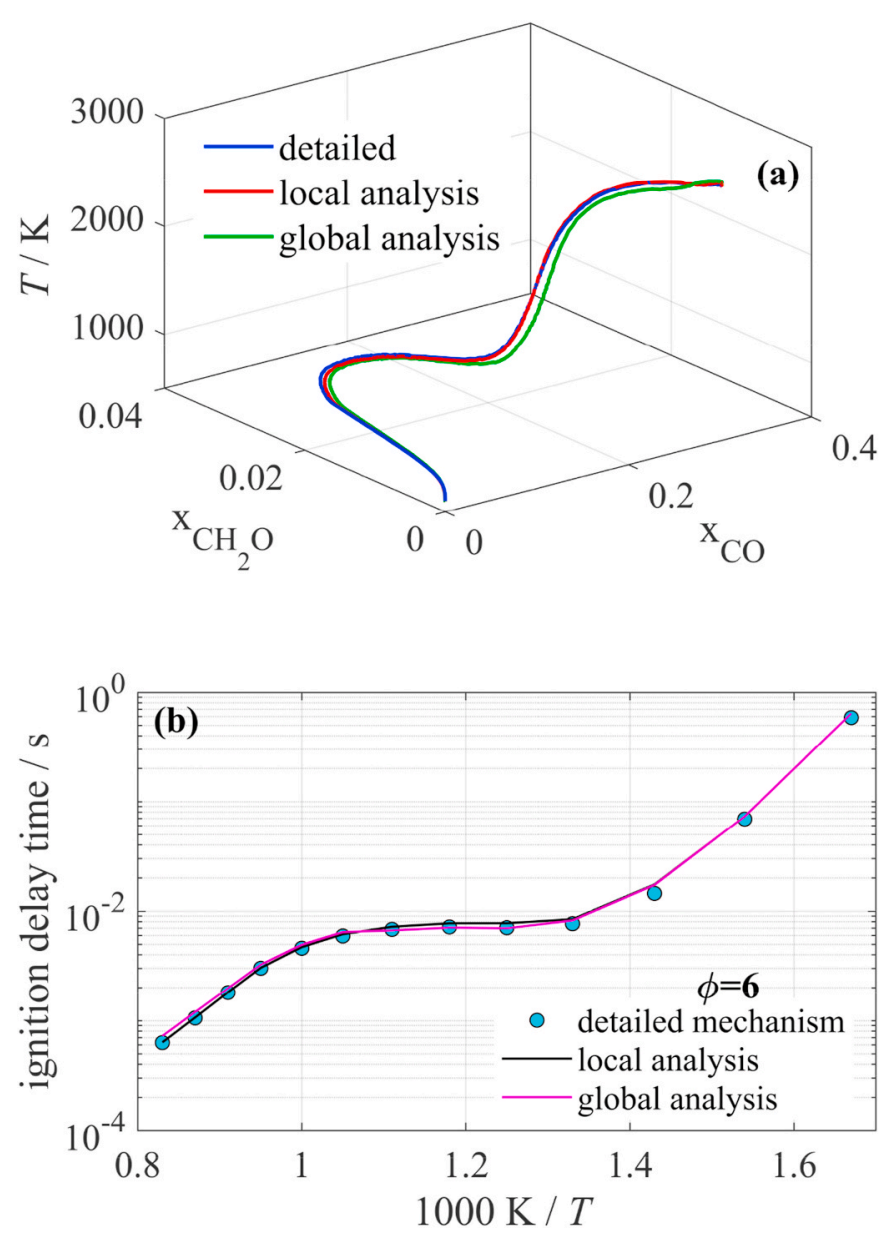

Fig. 5. Comparison of simulation results with the three versions of PolyMech, detailed, skeletal based on local analysis, and based on global analysis. (a) Temporal evolution in the thermochemical state space projected onto the coordinates $T, x_{\mathrm{CH} 2 \mathrm{O}}$, and $x_{\mathrm{CO}}$ for a $\mathrm{CH}_{4} / \mathrm{DME}(10 \% \mathrm{DME})$ at $\phi=2, p=10$ bar and $T=600 \mathrm{~K}$. (b) Ignition delay times for the same mixture at $\phi=6$ and $p=10 \mathrm{bar}$.

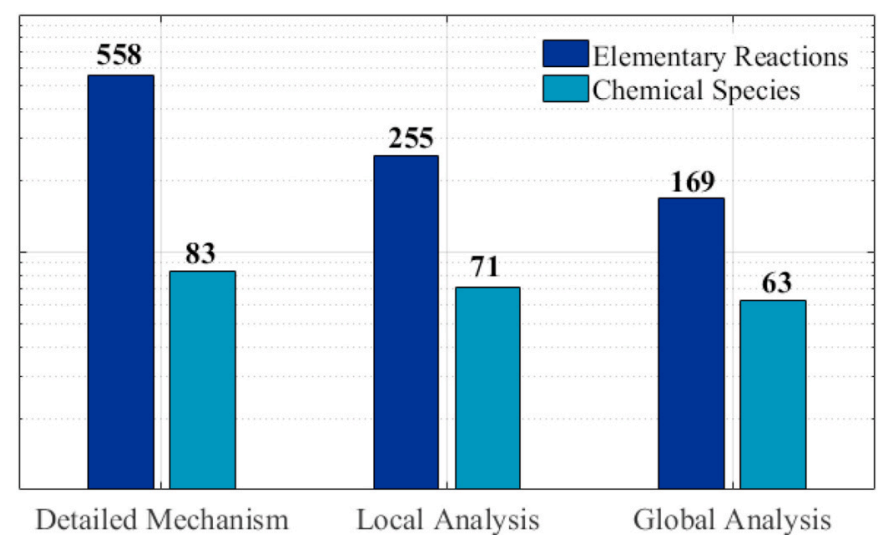

Fig. 6. Comparison of the number of reactions and species in the skeletal models from the global and local analysis with the detailed version of PolyMech [23] for a $\mathrm{CH}_{4} /$ DME-Mixture.

\subsection{Validation experiments}

\subsubsection{Ignition delay and onset of conversion}

Ignition delay times are valuable validation targets for reaction mechanisms describing the combustion in engines. Fig. 8 shows experimental results obtained in shock tubes at $\phi=2$ for methane with 


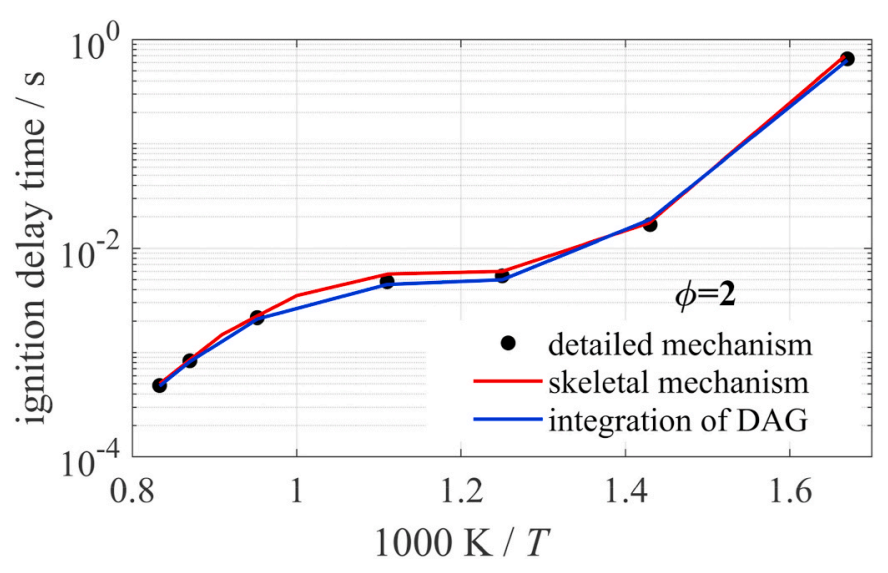

Fig. 7. Comparison of the ignition delay times from the detailed version of PolyMech with the ones from the skeletal mechanism and the implicit form of the global analysis for a $\mathrm{CH}_{4} / \mathrm{DME}(10 \% \mathrm{DME})$ at $\phi=2$ and $p=10$ bar.

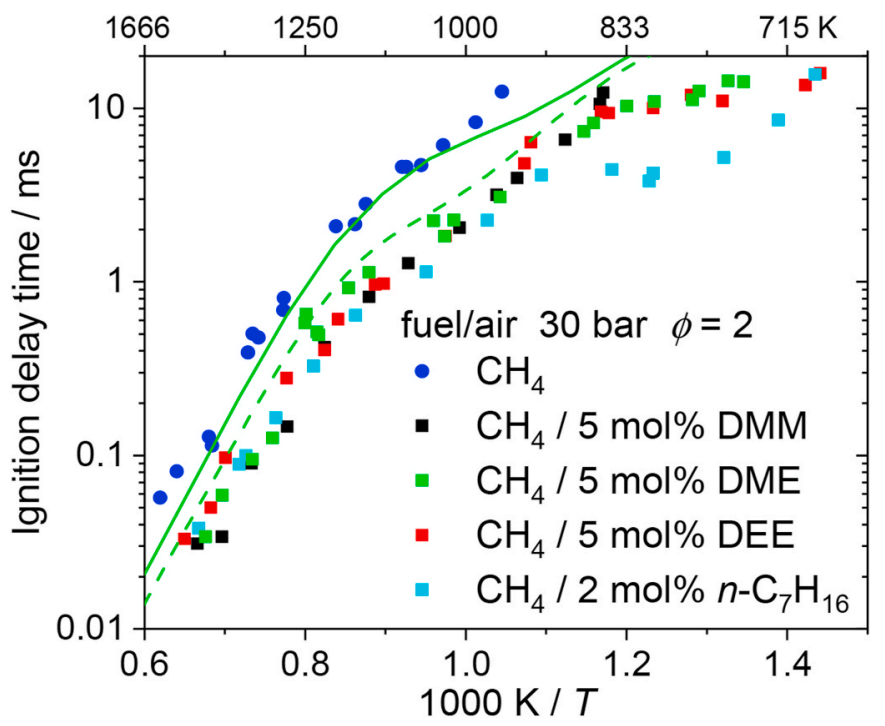

Fig. 8. Measured and simulated ignition delay times of methane/additive mixtures at $\phi=2$ and $p=30$ bar. Simulations are for 5\% DME addition. Full green line: Simulation with PolyMech [23]. Dashed green line: Simulation with Burke et al. [20]. The measured data were published in Refs. [23,26,49]. (For interpretation of the references to color in this figure legend, the reader is referred to the Web version of this article.)

selected additives (DME, DEE, DMM, and n-heptane). All additives lead to a broadly similar reduction of the IDT at a given temperature, except that $\mathrm{n}$-heptane shows a pronounced negative temperature coefficient (NTC) behavior. Conversely, any of the additives reduces the temperature required for an IDT of $2 \mathrm{~ms}$ from $1250 \mathrm{~K}$ to about $1000 \mathrm{~K}$. While the molar concentration of n-heptane is lower than for the ethers, the fraction of added carbon atoms is comparable. These data enable validating reaction mechanisms at engine-typical conditions. Experiments at 20 bar with $20 \%$ DME showed very good agreement with simulations using the mechanism of Burke et al. [20]. Measured IDTs in the RCM show very good agreement with shock-tube data in the small overlapping temperature range near $850 \mathrm{~K}$ and allow extending the validation range to lower temperatures [23]. Overall, a preliminary conclusion is that the additives investigated here are to some extent interchangeable in their effect on global kinetics at $\phi=2$ and can be selected due to other criteria, such as thermodynamics, practical handling, sustainability, or simply cost. However, the influence of the additive at different equivalence ratios and on product formation is not clear yet.
Next, very fuel-rich conditions with $\phi=10$ are considered. Compared to $\phi=2$, these conditions may offer the advantage of greater exergy storage by the formation of higher hydrocarbons. For this purpose, very fuel-rich mixtures must be used to minimize the heat production so that the final temperature after ignition remains too low for significant soot formation. IDTs measured in a high-pressure shock tube and an RCM are shown in Fig. 9. The simulations with PolyMech [23] agree well with the experiments.

The effect of different additives is seen in the flow reactor, as shown in Fig. 10. If methane in a mixture with an additive is converted at lower temperatures than without additive, the additive has activated the methane conversion. For $5 \%$ n-heptane or DME addition, Fig. 10 shows that the methane conversion is already increased at temperatures between 523 and $673 \mathrm{~K}$. If $9 \%$ ethane and $1 \%$ propane are added to methane to represent the composition of typical natural gas, compared to the reaction of neat methane the effect is minor. Ethane and propane are converted at slightly lower temperatures than methane (not shown here), but without noticeable chemical interaction with methane. The addition of $20 \%$ ethanol increases the methane conversion only at temperatures of $773 \mathrm{~K}$ and above. These results fit well with the findings in shock tubes and RCMs but cover the lower temperature range that is important for low-temperature conversion of the fuel before ignition in the compression stroke of an engine. It could be shown, for example, that methane exhibits a region of weak NTC behavior at low temperatures and high pressures that may influence its ignition in the engine [50].

\subsubsection{Kinetics of product formation}

Product formation and composition is especially important in the context of polygeneration. The product formation was studied with four complementary techniques: Time-resolved infrared diode-laser absorption measurements of $\mathrm{CO}$ concentrations in a shock tube [34], gas-chromatography of time-resolved samples from a RCM [23], GC/MS (gas chromatography/mass spectrometry) in fast-drawn samples from a high-pressure shock tube (in the cooling phase after the reflected shock wave) [23], and time-of-flight mass spectrometry (TOF-MS) in a high-pressure flow reactor [23]. All techniques confirmed that syngas ( $\mathrm{CO}$ and $\mathrm{H}_{2}$ ) is the main product at $\phi=2$. Simulations with PolyMech predicted the product formation very well. Fig. 11 shows fuel consumption and product formation measured in a flow reactor. The fuel

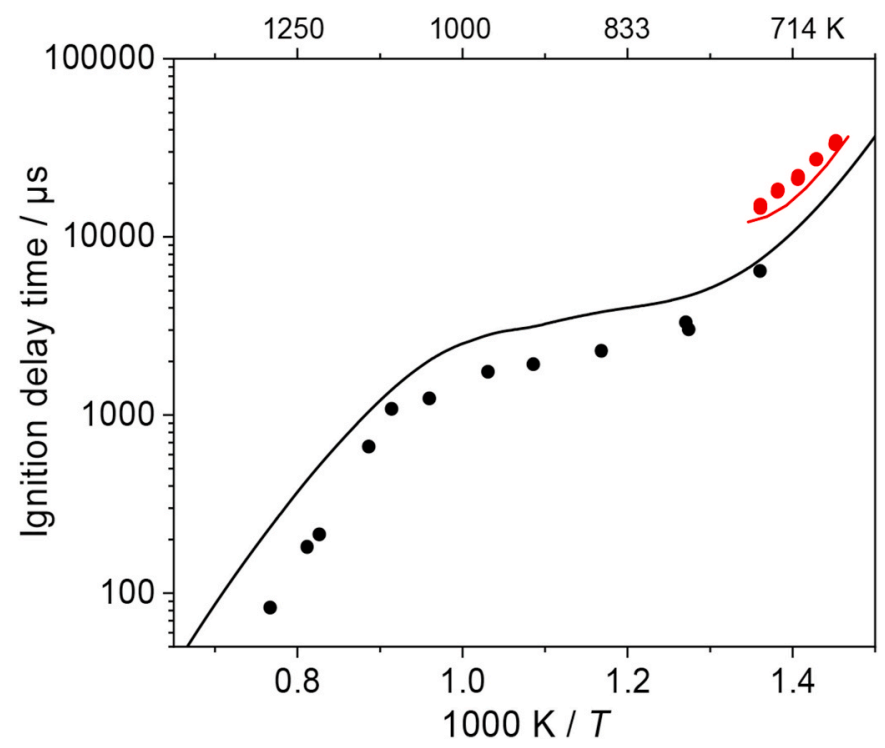

Fig. 9. Ignition delay times of a $10 \% \mathrm{DME} / 90 \% \mathrm{CH}_{4}$ mixture at $\phi=10$. Black circles: Shock tube at $p=30$ bar, black line: PolyMech [23] simulation of the shock-tube data, red circles: RCM at $p=10$ bar, red line: PolyMech [23] simulation of the RCM data. (For interpretation of the references to color in this figure legend, the reader is referred to the Web version of this article.) 


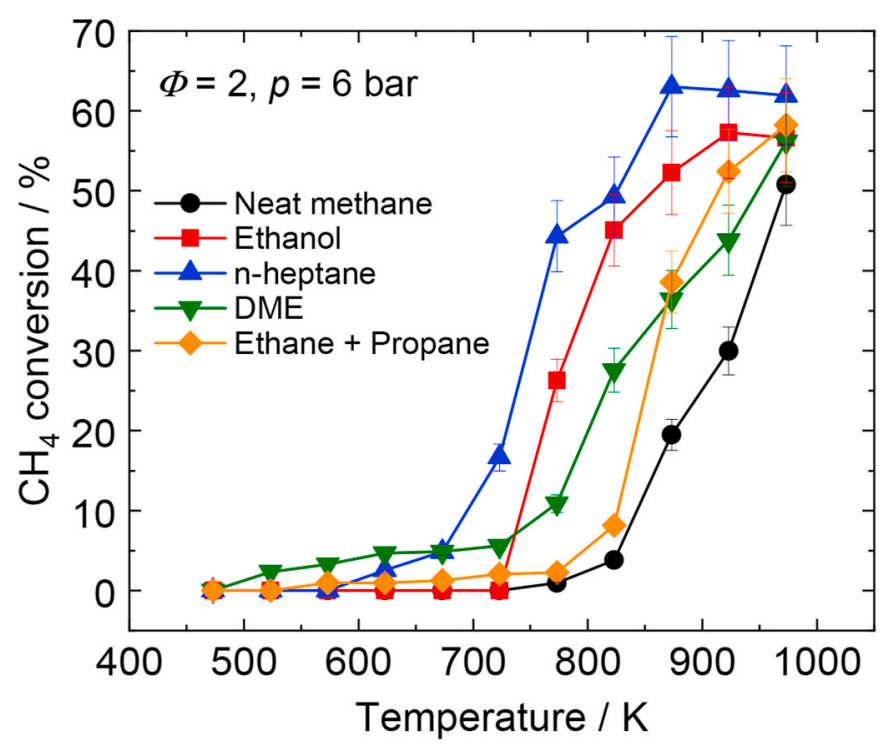

Fig. 10. The temperature-dependent methane conversion in mixtures with different additives. All for $\phi=2, p=6$ bar and an argon dilution of $\sim 90 \%$. The additive/fuel ratios are 5/95 (n-heptane [51] and DME [23]), 10/90 (natural gas [52]) and 20/80 (ethanol). Neat methane data are from Ref. [52].

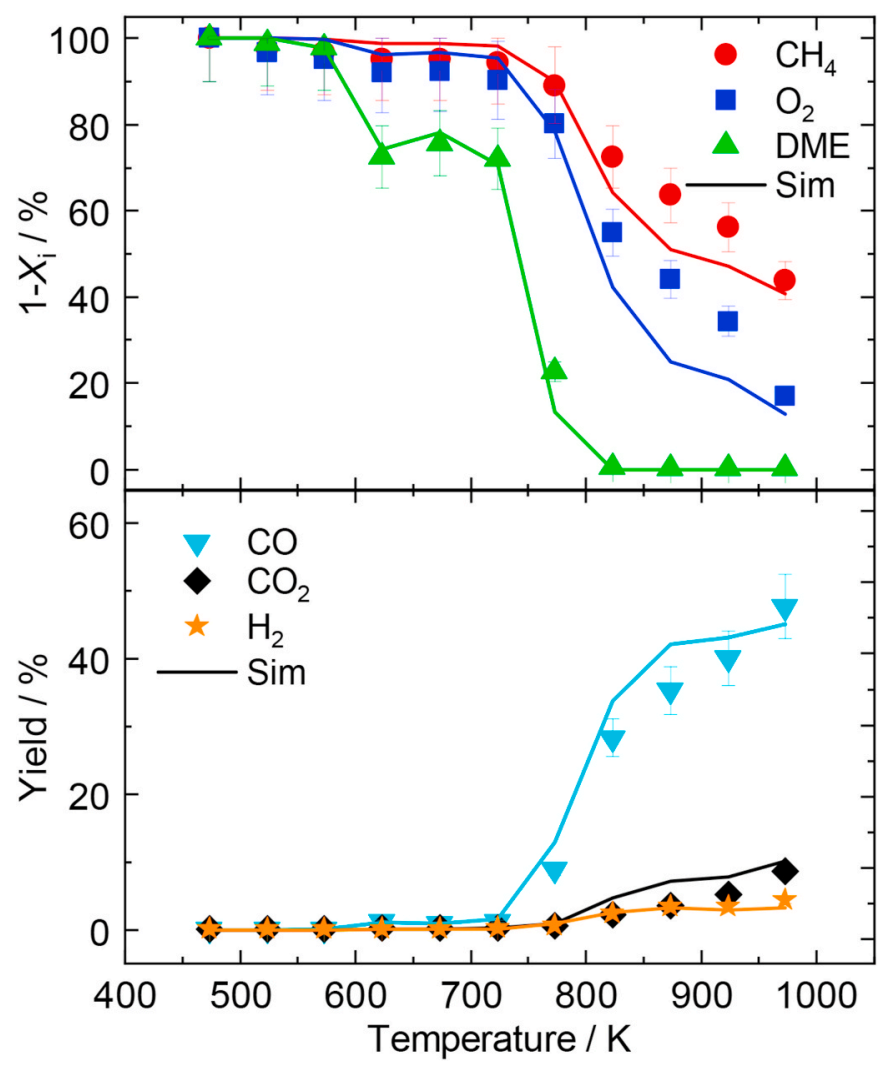

Fig. 11. Measured and simulated remaining educts $1-X$ and yields $Y$ in the flow reactor at $p=6$ bar and $\phi=2$. Inlet mixture: $4.69 \% \mathrm{CH}_{4}, 0.25 \% \mathrm{DME}, 5.06 \%$ $\mathrm{O}_{2}, 90 \%$ Ar. The residence time varies with temperature from 14.5 to $7.6 \mathrm{~s}$ at 473 and $973 \mathrm{~K}$, respectively.

consumption and the product formation show an NTC behavior, which was also observed in the IDT measurements.

Also for ultra-rich mixtures, product composition measurements were performed in the high-pressure shock tube, the RCM [53], and the flow reactor. The shock-tube results at $\phi=10$ are shown in Fig. 12. They

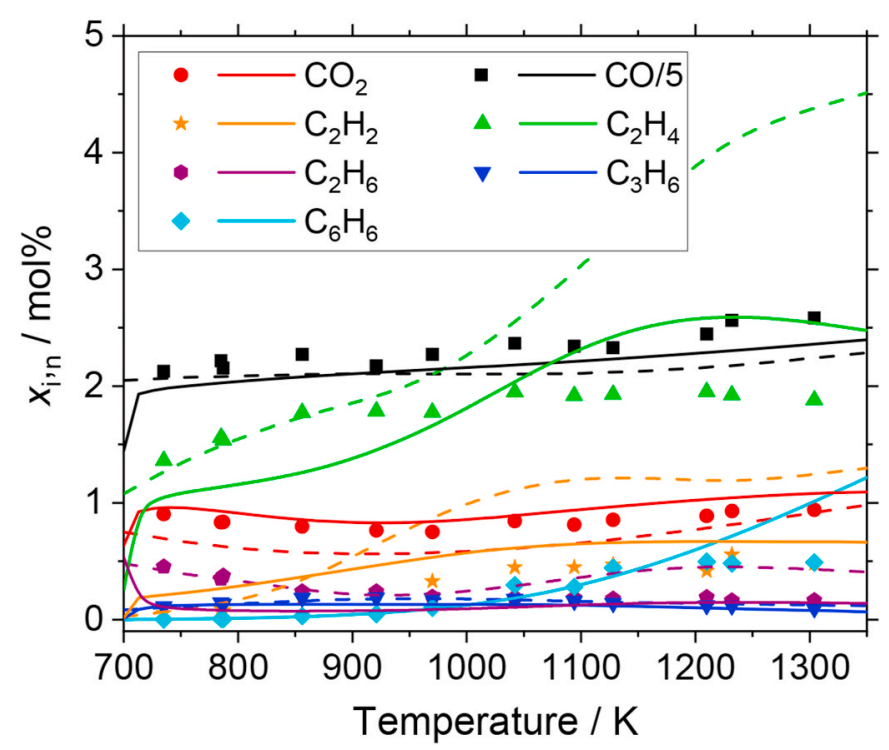

Fig. 12. Product mole fractions after ignition of a $\mathrm{CH}_{4} / 10 \mathrm{~mol} \% \mathrm{DME} / \mathrm{air}$ mixture at $\phi=10$, and 30 bar. Symbols show shock-tube data, full lines show simulations with an updated version of PolyMech [23], dashed lines with the mechanism of Burke et al. [20].

were obtained by GC/MS analysis after fast sampling in the cooling phase and are relative to neon as an internal standard. $\mathrm{H}_{2}$ could not be detected by the GC/MS system. Here, 10\% DME were used as an ignition promoter, but with other additives (DEE, DMM, and n-heptane) the product composition was almost the same [26]. About half of the consumed carbon is converted to $\mathrm{CO}$, the other half to higher hydrocarbons. Simulations show that almost constant product concentrations are reached about $2 \mathrm{~ms}$ after ignition except for benzene (still increasing) and acetylene (still decreasing). Comparing the experimental results with $\mathrm{CH}_{4} / \mathrm{DME}$ mixtures with different mechanisms from the literature $[17,18,20]$, it is found that most show large deviations from the corresponding experimental results, especially for acetylene and benzene. This is not surprising because the mechanisms were not developed for these fuel-rich conditions and often do not contain benzene formation chemistry. For other additives, only the mechanism of Cai and Pitsch [33] can predict the observed product composition of $\mathrm{CH}_{4}$ /additive mixtures well [26] (for $\mathrm{CH}_{4} / \mathrm{n}$-heptane). With PolyMech, the predictions of $\mathrm{CO}_{2}$ and benzene concentrations initially did not agree well with shock tube measurements [23]. This was greatly improved by replacing the rate coefficient of $\mathrm{CO}+\mathrm{HO}_{2}=\mathrm{CO}_{2}+\mathrm{OH}$ with a recent value of You et al. [54] and by adding benzene consumption reactions (see Fig. 12). The mechanism of Burke et al. [20] overpredicts the concentrations of C2 species because it contains only species up to C3 and no benzene formation chemistry.

Fig. 13 shows time-resolved RCM results for an undiluted $90 \% \mathrm{CH}_{4} /$ $10 \%$ DME mixture at 10 bar and temperatures between 714 and $738 \mathrm{~K}$. Simulations were performed with a multi-zone model and PolyMech [23]. The fuel consumption and the product formation are well predicted [55]. The additive is consumed faster than methane and initiates methane consumption. The main products are $\mathrm{H}_{2}$ and $\mathrm{CO}$, but higher hydrocarbons are also detected.

The results from the flow reactor, shown in Fig. 14, confirm those from shock tube and RCM: There is an NTC region, the additive is consumed faster and more completely than methane, the main products is syngas but C2 and C3 hydrocarbons are also found. Simulations with the PolyMech [23] predict the temperature-dependent fuel consumption and product formation very well.

A comparison of experimental results from the flow reactor with simulations using PolyMech is shown in Fig. 15 for mixtures of 5\% DME in methane at 6 bar and $\phi=2$ and 10. The shaded area represents the 


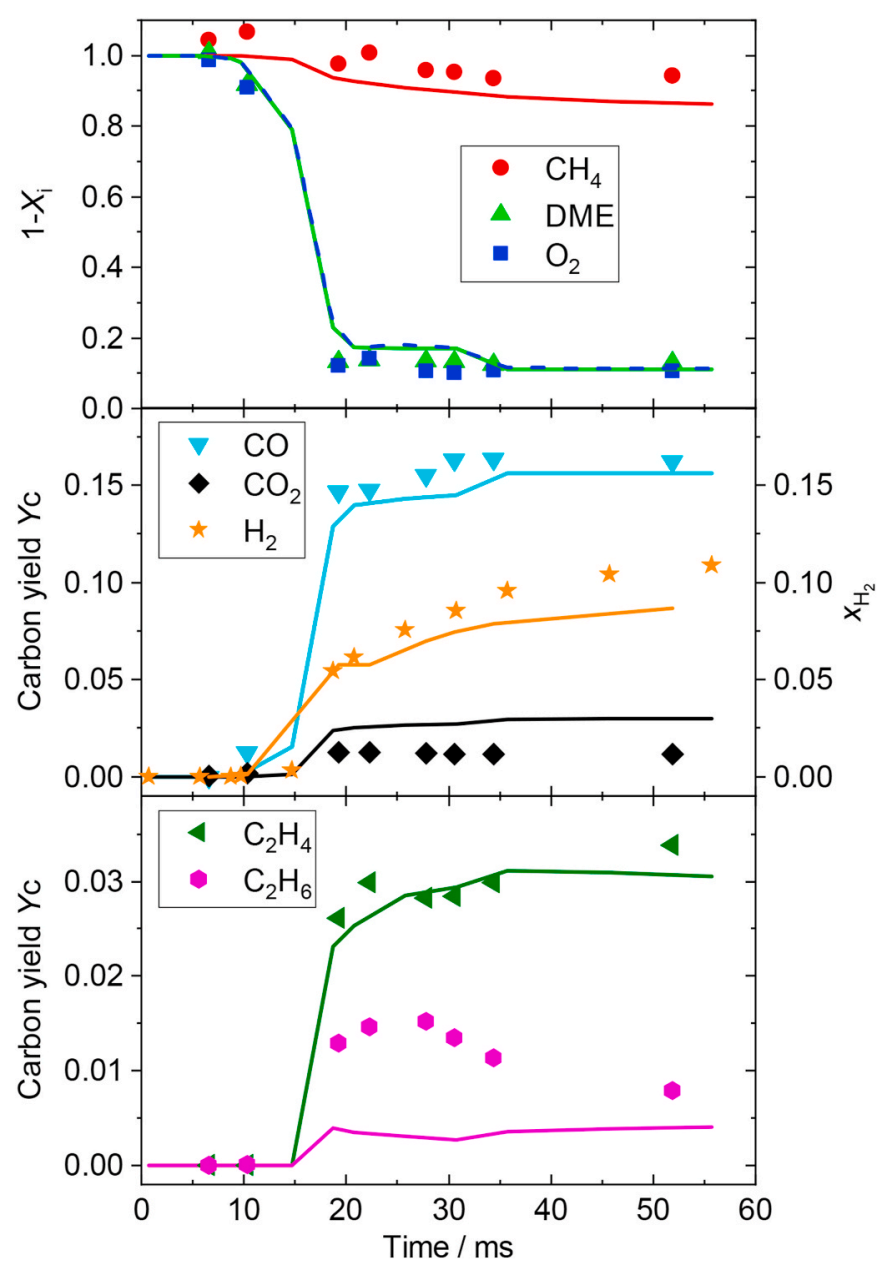

Fig. 13. Measured and simulated remaining educts $1-X$ and yields $Y$ in the RCM compressing an undiluted $90 \% \mathrm{CH}_{4} / 10 \%$ DME mixture $(\phi=10)$ to 10 bar and temperatures between 714 and 738 K. Simulations with PolyMech [23].

confidence interval of the experiments. Overall, the agreement between experimental and simulation is very good for $\phi=10$, but not as good for $\phi=2$.

In the flow reactor, numerous species concentrations were quantitatively detected at the reactor outlet with GC/MS as a function of equivalence ratio and temperature. The results for a 5\% heptane/95\% $\mathrm{CH}_{4}$ mixture are condensed into the semi-quantitative map shown in Fig. 16. Such maps can be useful to find operating conditions for the production or avoidance of specific species. For example, Fig. 16 shows that moderately high equivalence ratios and high temperatures are favorable for the formation of synthesis gas, while high temperatures and high equivalence ratios lead to high ethylene yields. The yields of oxygenated species like ketones can be considerable, but this is limited to low temperatures with relatively low methane conversion. Benzene starts to form at temperatures around $900 \mathrm{~K}$ and peaks at $\phi=20$ in the investigated temperature range. Its yield could be increased by increasing the temperature, but with the risk of further conversion towards PAHs and soot.

Overall, PolyMech is a very good mechanism for these unusual conditions and often predicts species profiles better than, or at least as good, as the discussed alternative mechanisms, most of which include considerably more species.

\subsection{Energy storage by methane pyrolysis}

The conversion of mechanical to chemical energy is also of interest to

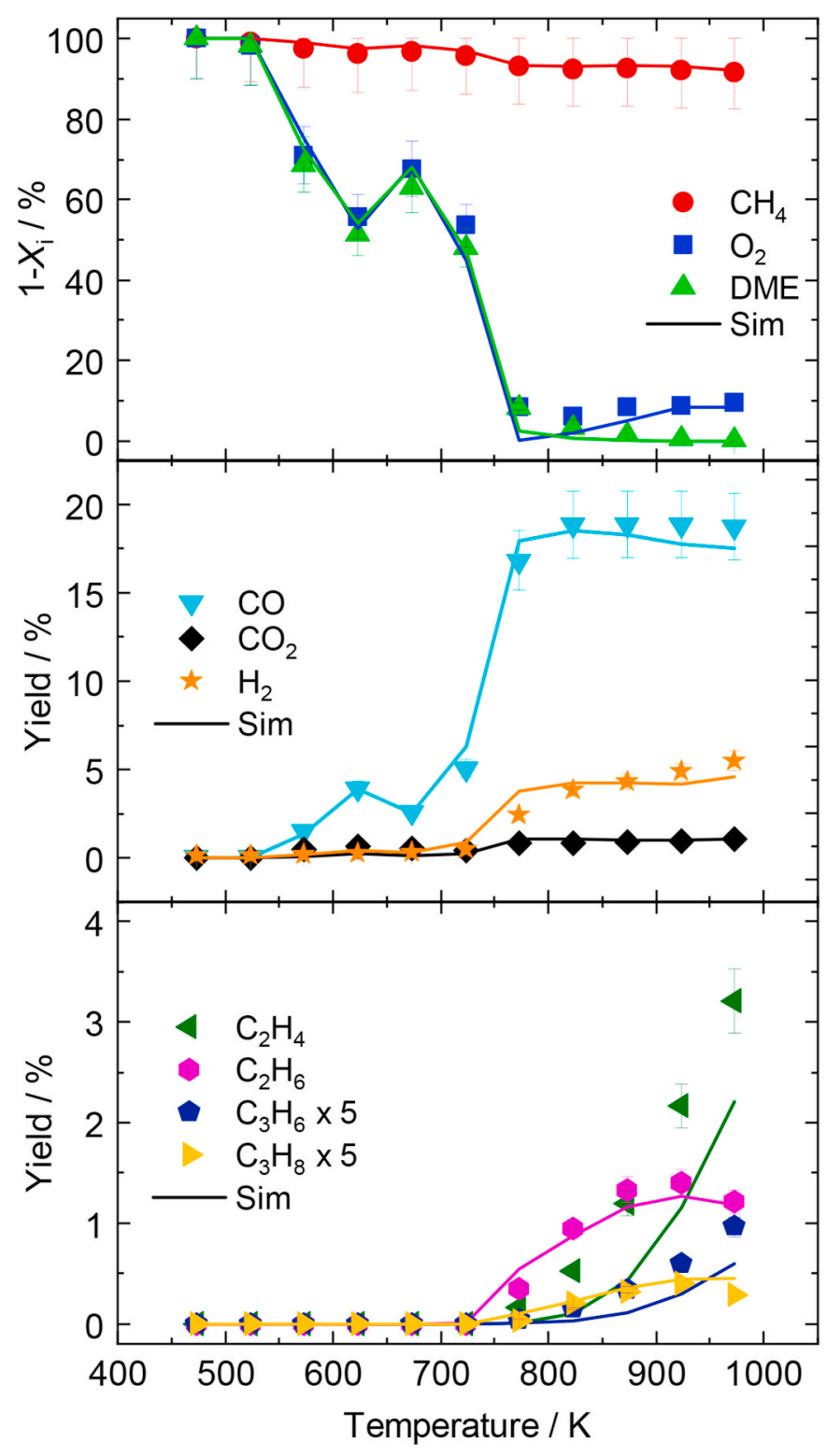

Fig. 14. Measured and simulated remaining educts $1-X$ and yields $Y$ in the flow reactor at $p=6$ bar and $\phi=10$. Inlet mixture: $7.44 \% \mathrm{CH}_{4}, 0.83 \% \mathrm{DME}, 1.74 \%$ $\mathrm{O}_{2}, 90 \%$ Ar. The residence time varies with temperature from 14.5 to $7.6 \mathrm{~s}$ at 473 and 973 K, respectively. Simulations with PolyMech [23].

store energy. It could be carried out in engines, which then mainly act as compressors. If electrical energy is available, an electric motor would convert that into mechanical work, which would then be used in a compression-expansion cycle in a piston engine. Simple hydrocarbons could then be converted endothermically to higher-enthalpy hydrocarbons and $\mathrm{H}_{2}$. The energy input for the endothermal reaction would be provided through the work supplied in the compression stroke. At first sight, it may seem preferable to use pure hydrocarbons like methane. For methane conversion, temperatures between 1300 and $2000 \mathrm{~K}$ are needed, according to equilibrium calculations and experiments [56-58], with $\mathrm{H}_{2}$, ethylene, benzene, and acetylene being the main products. However, the heat capacities of pure hydrocarbons are very high. Thus, at engine-typical initial temperatures and compression ratios, the TDC temperatures are far too low to obtain a measurable conversion [56]. At a compression ratio of 25 , an initial temperature of $720 \mathrm{~K}$ would be needed in an adiabatic system to obtain temperatures high enough for high conversion. Alternatively, sufficiently high temperatures for pyrolysis can be reached by dilution with an atomic inert gas (most readily 

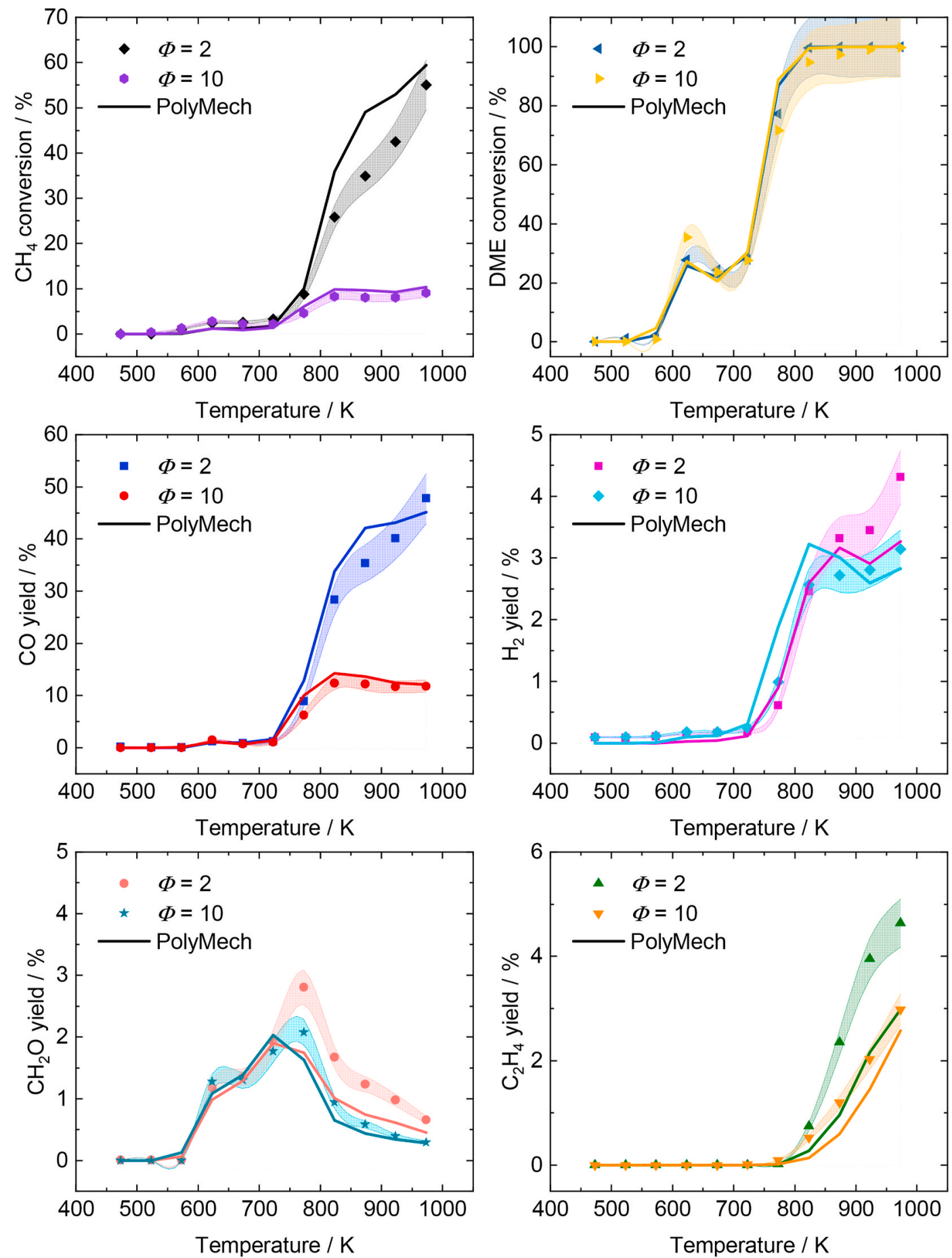

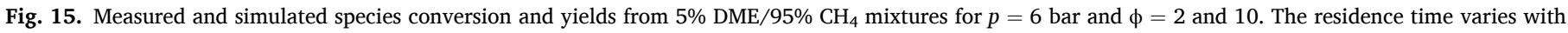
temperature from 14.5 to $7.6 \mathrm{~s}$ at 473 and $973 \mathrm{~K}$, respectively. The experiments were performed in the flow reactor, PolyMech was used in the simulations.

available is argon), decreasing the heat capacity of the gas mixture.

The kinetics of the process can again be investigated as described above, with engine parameters modified in favor of the pyrolysis process. Mainly, a compression ratio of $\varepsilon=22$ and an engine speed $N=$ $3000 \mathrm{rpm}$ were chosen. The reactions were simulated using the Polimi mechanism [59], an elementary reaction mechanism that includes 484 species up to $\mathrm{C}_{20}$ and 19341 reactions. These high-molecular-weight species are not yet included in PolyMech. A thermodynamic analysis was included, in particular a calculation of the chemical and physical exergy of the gas mixture according to Refs. [56]. The storable energy is then calculated as the difference of the exergy between reactant and product gas. The storage efficiency is the storable energy divided by the supplied work. To find engine parameters that favor the pyrolysis process, the process can be kinetically investigated as described in Section 2.2 .

The results of a typical simulation are shown in Fig. 17 for an intake temperature of $423 \mathrm{~K}$, an intake pressure of $2 \mathrm{bar}$, and an intake argon mole fraction of $96 \%$. The consumption of methane at temperatures above $1300 \mathrm{~K}$ and the formation of the main products as a function of the crank angle are seen. The main products are hydrogen and higher hydrocarbons like acetylene, ethylene, and benzene. The model also shows that acetylene reacts between 180 and $200^{\circ} \mathrm{CA}$ to soot precursors like 


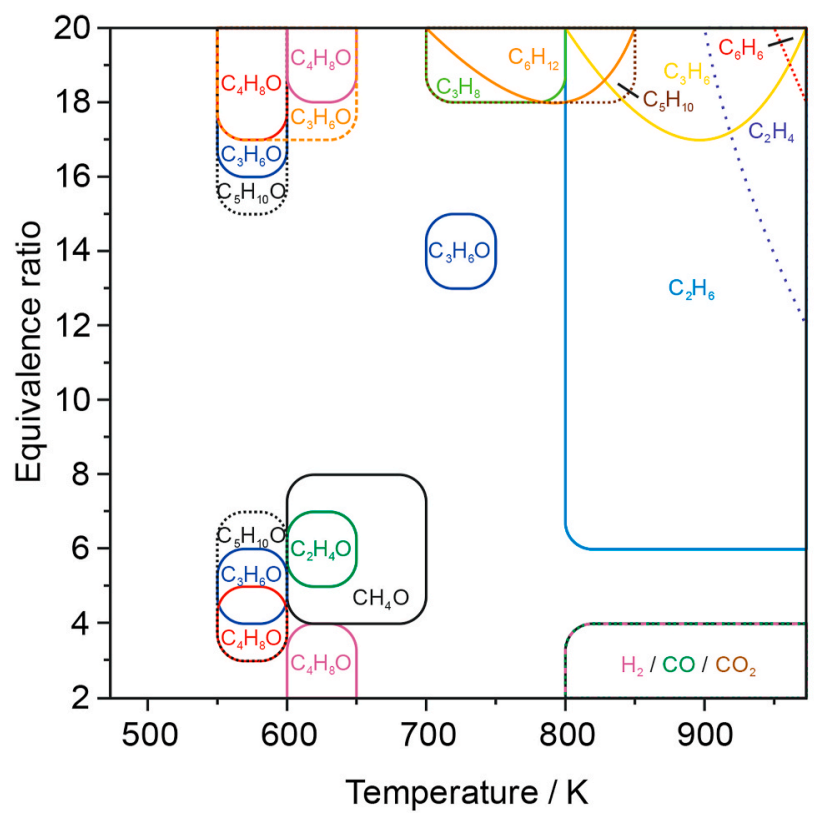

Inorganic species

- - Hydrogen (6\%)

......... Carbon monoxide (55\%)

Carbon dioxide $(40 \%)$

Alkanes / Alkenes

.... Ethylene $(9 \%)$

- Ethane $(2.5 \%)$

-

- Propane $(0.5 \%)$

........ Cyclopentane $(0.3 \%)$

cyclohexane $(0.2 \%)$

Aldehydes

- Acetaldehyde (2.6\%)

ropanal $(2 \%)$

- Butanal (1.7\%)

Ketones

- Acetone (5\%)

- Butanone $(7.5 \%)$

......... 2-Pentanone $(8.5 \%)$

Alcohols

- Methanol (3\%)

Aromatics

.......... Benzene (0.5\%)

Temperature / K

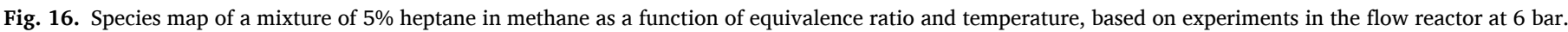

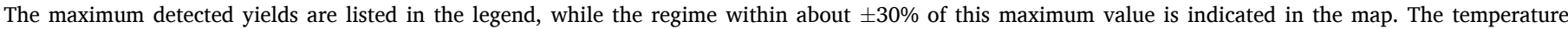
resolution in the map is $50 \mathrm{~K}$ [51].

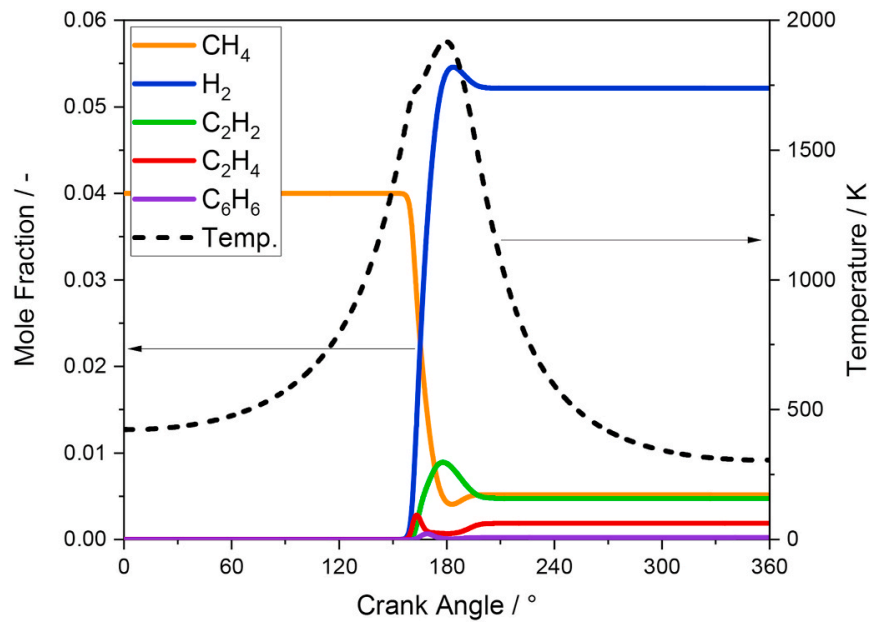

Fig. 17. Mole fractions and temperature as a function of crank angle for methane at intake conditions of $T_{0}=423 \mathrm{~K}, p_{0}=2$ bar, and $x_{\mathrm{Ar}}=0.96 . \varepsilon=22$, $N=3000 \mathrm{rpm}$.

$\mathrm{C}_{20} \mathrm{H}_{10}$ and $\mathrm{C}_{20} \mathrm{H}_{16}$, and methane is formed again. After $200^{\circ} \mathrm{CA}$, the mixture composition is "frozen" by the decreasing temperatures in the expansion stroke. Overall, for these intake parameters, $\mathrm{a} \mathrm{CH}_{4}$ conversion of $90 \%$ is predicted together with yields for acetylene, ethylene, and benzene of 24,9 , and $3 \%$, respectively. The exergy of the mixture was increased by about $6 \%$.

The pyrolysis reaction, and thus the methane conversion strongly depends on temperature. From literature, it is known that the pyrolysis of methane starts at temperatures of $1300 \mathrm{~K}$ [60]. Methane conversion in this process is mainly controlled by the temperatures at the end of the compression stroke. Fig. 18 shows the methane conversion as a function of intake temperature and intake argon mole fraction (the remainder of the mixture is methane). The graph also includes isothermal curves of the TDC temperature. It can be seen that higher argon mole fractions with lower intake temperatures lead to the same TDC temperature and the same conversion as lower argon mole fractions and higher intake

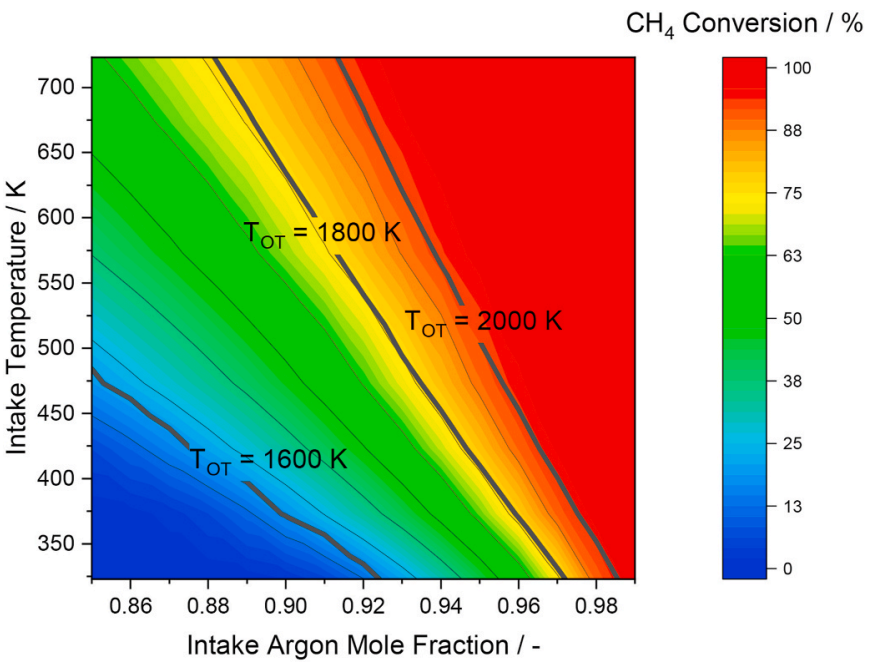

Fig. 18. $\mathrm{CH}_{4}$ conversion (colored contours) and top dead center temperature (thick black lines) as a function of the intake temperature and the intake argon mole fraction. $p_{0}=2$ bar, $\varepsilon=22, N=3000 \mathrm{rpm}$.

temperatures. The isothermal curves of the TDC temperatures are parallel to the $\mathrm{CH}_{4}$ conversion. For a TDC temperature of $1600 \mathrm{~K} 15 \%$ of methane are converted. This is significantly less than what would be expected in chemical equilibrium at that temperature, i.e., conversion is kinetically limited by the short reaction times in the engine (but most stationary engines actually run slower than $3000 \mathrm{rpm}$ ). A methane conversion of $80 \%$ can be reached at TDC temperatures of $1800 \mathrm{~K}$. This is reached for example by an intake parameter combination of $97 \%$ argon and $323 \mathrm{~K}$, but also for $89 \%$ argon and $723 \mathrm{~K}$.

The storage power depends on the methane conversion, but also on the intake dilution. In order to examine whether high argon dilutions or high intake temperatures are more favorable for the process, the storage power and the storage efficiency are compared as a function of intake argon mole fraction for three different intake temperatures of 323,423 , and $523 \mathrm{~K}$ at an intake pressure of 2 bar. Fig. 19 shows that for all intake 


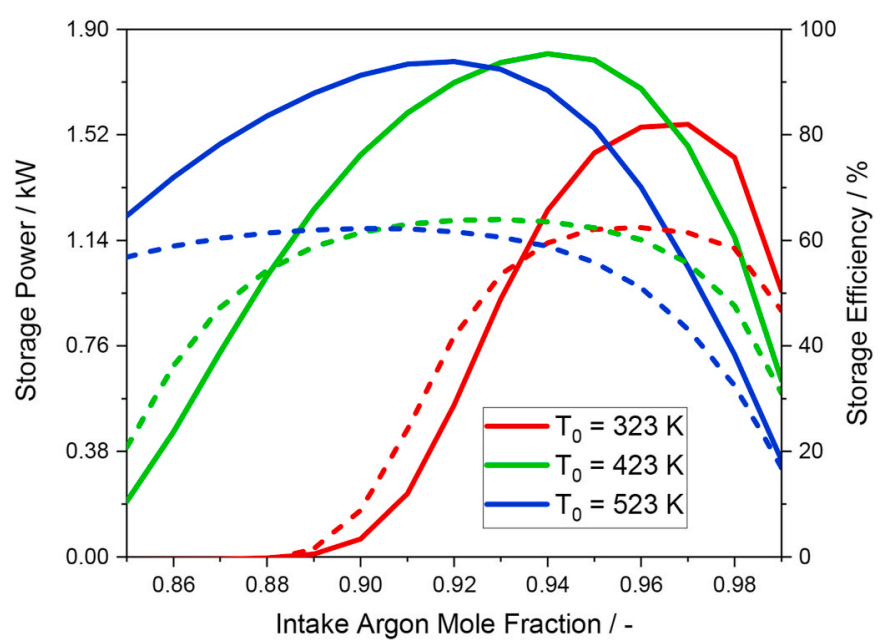

Fig. 19. Storage power (solid lines) and efficiency (dashed lines) as a function of intake argon mole fractions for different intake temperatures $T_{0} . p_{0}=2 \mathrm{bar}$, $\varepsilon=22, N=3000 \mathrm{rpm}, \Delta V=400 \mathrm{~cm}^{3}$.

temperatures storage power and efficiency decrease for both the lowest and the highest argon dilutions. This is caused by the low conversion with lower argon dilution and by the small fraction of methane in the mixture when the argon dilution is too high. With increasing intake temperatures, the effect is less pronounced, and the maximum storage power and efficiency shift to lower argon dilutions. The storage power has a local maximum at $T_{0}=423 \mathrm{~K}$ and $x_{\mathrm{Ar}}=0.94$ of $1.8 \mathrm{~kW}$ for $N=$ $3000 \mathrm{rpm}$ and $\Delta V=400 \mathrm{~cm}^{3}$ in this four-stroke engine. Unexpectedly, the maximum storage power decreases for intake temperatures higher than $423 \mathrm{~K}$. This is due to the formation of soot precursors and reformation of $\mathrm{CH}_{4}$. The maximum efficiencies are between 60 and $63 \%$, which is promising.

Experiments were performed to validate the simulation results. The pyrolysis of methane (1 and $5 \mathrm{~mol}_{\%} \mathrm{CH}_{4}$ in Ar/He mixture, $p=12-26$ bar, $T=1350-1750 \mathrm{~K}$ [53]) and natural gas (5\% NG surrogate, with the composition described in 3.2.2) in Ar/He, $p=21-31$ bar, $T=$ $1380-1690 \mathrm{~K}$ [61]) was studied in the RCM. After expansion by rapid retraction of the piston [55], the products were analyzed with a GC. The temperature dependency of the methane pyrolysis and product formation are shown in Fig. $20 . \mathrm{H}_{2}, \mathrm{C}_{2} \mathrm{H}_{2}$, and $\mathrm{C}_{2} \mathrm{H}_{4}$ are the main products. The $\mathrm{GC}$ used here cannot detect benzene. In the temperature range investigated here, the conversion of methane and the formation of products

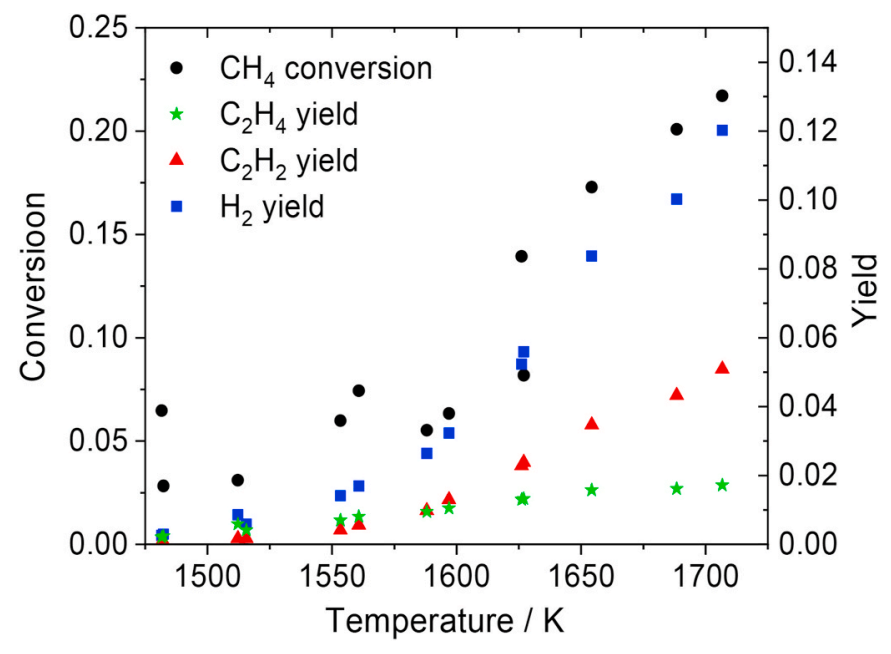

Fig. 20. Measured species conversion and yields in an RCM for a $5 \mathrm{~mol}-\% \mathrm{CH}_{4} /$ $90 \mathrm{~mol}-\% \mathrm{Ar} / 5 \mathrm{~mol}-\%$ He mixture at 18 bar [53]. slightly decreases with increasing pressure [61]. The conversion decreases also with increasing methane concentration due to the higher temperature decrease (higher endothermicity) with higher concentrations [61]. The trends for pressure and temperature dependency observed for methane pyrolysis were found also for natural-gas pyrolysis. As found in the kinetics investigations, ethane and propane decompose much faster than methane.

Simulations show that high conversions can be achieved for concentrations of up to $10 \%$ methane in argon. These $\mathrm{CH}_{4} / \mathrm{Ar}$ mixtures were studied in shock tubes [62] and an RCM [53]. In adiabatic systems, a characteristic feature of this methane pyrolysis is a fast decrease in the temperature due to the formation of products with a higher enthalpy (energy storage process), which leads to a quasi-equilibrium at a relatively low temperature with negligible further methane consumption. An end-product analysis alone is not sufficient for the validation of different mechanisms because it cannot distinguish how fast the quasi-equilibrium is reached. Therefore, we also performed time-resolved temperature and methane infrared absorption measurements. Species concentration measurements with GC/MS were performed in shock tubes at about 1.5 bar (single-pulse shock tube) and at 30 bar (with fast sampling). The results at 1.5 bar are shown in Fig. 21. The main detected product is $\mathrm{C}_{2} \mathrm{H}_{2}$, while other $\mathrm{C} 2$ as well as $\mathrm{C} 3, \mathrm{C} 4$ species, and benzene are formed in smaller amounts. The other main product, $\mathrm{H}_{2}$, could not be detected with our GC/MS system. The methane consumption and the product formation were well-predicted in simulations using PolyMech [23]. At 30 bar, similar results were observed, but the methane consumption curve shifted by about $300 \mathrm{~K}$ towards lower temperatures. The product composition shifted towards benzene such that about equal amounts of $\mathrm{C}_{2} \mathrm{H}_{2}, \mathrm{C}_{2} \mathrm{H}_{4}$, and benzene were observed. At the upper temperature end of the high-pressure measurements soot formation was observed. Species concentration measurements at about 1.5 and 30 bar were also performed in shock tubes for a natural-gas surrogate $\left(90 \mathrm{~mol} \% \mathrm{CH}_{4}, 9 \mathrm{~mol} \% \mathrm{C}_{2} \mathrm{H}_{6}, 1 \mathrm{~mol} \%\right.$ $\mathrm{C}_{3} \mathrm{H}_{8}$ ). The results were very similar to the methane pyrolysis. The products and the methane consumption were almost identical, but ethane and propane decomposed at significantly lower temperatures [63].

Mid-IR diode lasers were used for the time-resolved temperature and methane concentration measurements in a shock tube. $1 \% \mathrm{CO}$ was

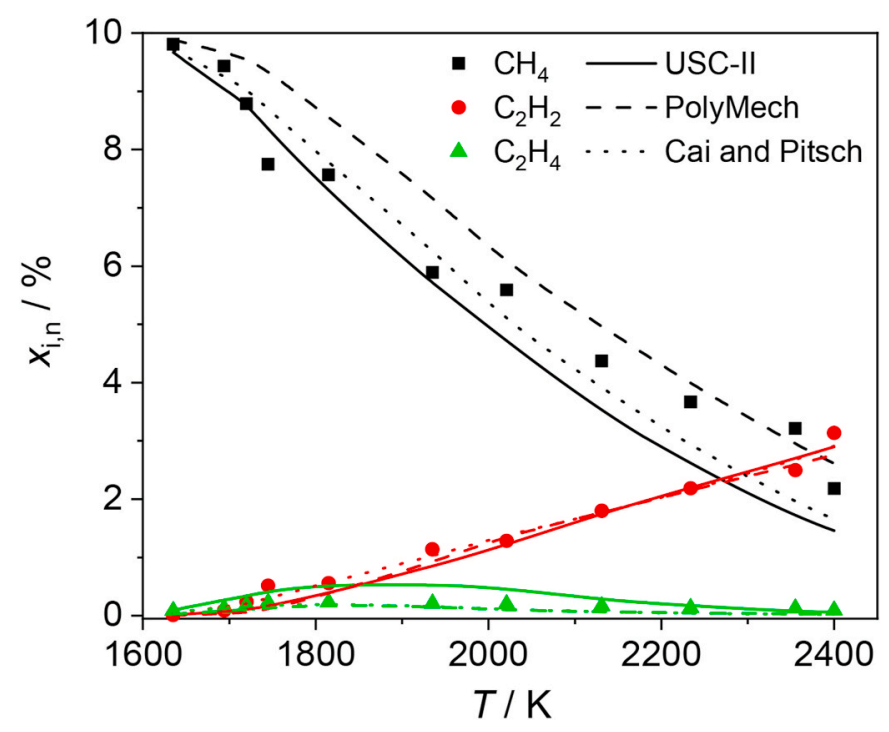

Fig. 21. Shock tube: Measured and simulated product species mole fractions of the pyrolysis of a $10 \mathrm{~mol} \% \mathrm{CH}_{4} / 90 \mathrm{~mol} \% \mathrm{Ar}$ mixture at about 1.5 bar. Symbols: experiment, solid line: simulations with USC mechanism [64], dashed line: simulation with PolyMech [23], dotted line: simulation with the Cai and Pitsch [33] mechanism. 
added to the mixture for temperature measurements with $\mathrm{CO}$ thermometry [62]. Typical temperature traces are shown in Fig. 22. A very fast temperature decrease can be observed for high initial temperatures, whereas at lower initial temperatures the temperature decreases more slowly. The temperature decrease is higher with higher methane consumption, as seen in Fig. 23. PolyMech predicts too slow a methane pyrolysis at lower temperatures. The predictions can be significantly improved by using a recently published rate coefficient for the $\mathrm{CH}_{4}$ $(+\mathrm{M})=\mathrm{CH}_{3}+\mathrm{H}$ reaction [58] (orange lines in Fig. 23). A general result of the pyrolysis experiments is that the experiments can be well reproduced by oxidation mechanisms.

In summary, energy can be stored via methane pyrolysis in piston engines, but because methane is very inert, high temperatures are needed. Due to the high heat capacity of methane these temperatures could only be established with unusual conditions, like high Ar dilution. This could in part be overcome with higher pre-heating combined with higher compression ratios. Other, less inert energy storage molecules like ethane may be an alternative worth investigating. The product-gas composition can be influenced by selecting suitable initial conditions and process parameters, which may make this approach interesting for the chemical industry.
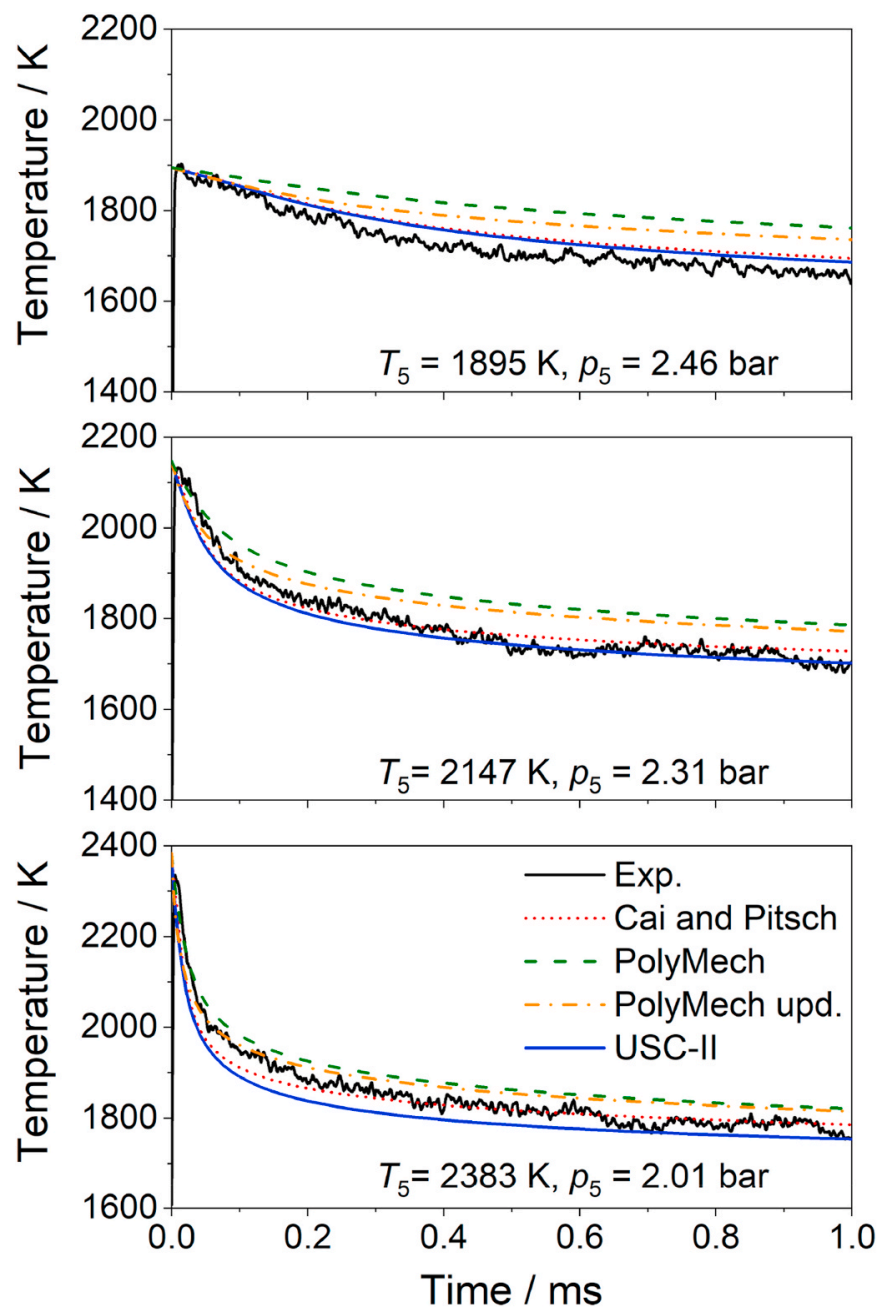

Fig. 22. Measured temperatures during the pyrolysis of a $10 \% \mathrm{CH}_{4} / 1 \% \mathrm{CO} /$ $20 \%$ He mixture in Ar in the shock tube compared with simulations.

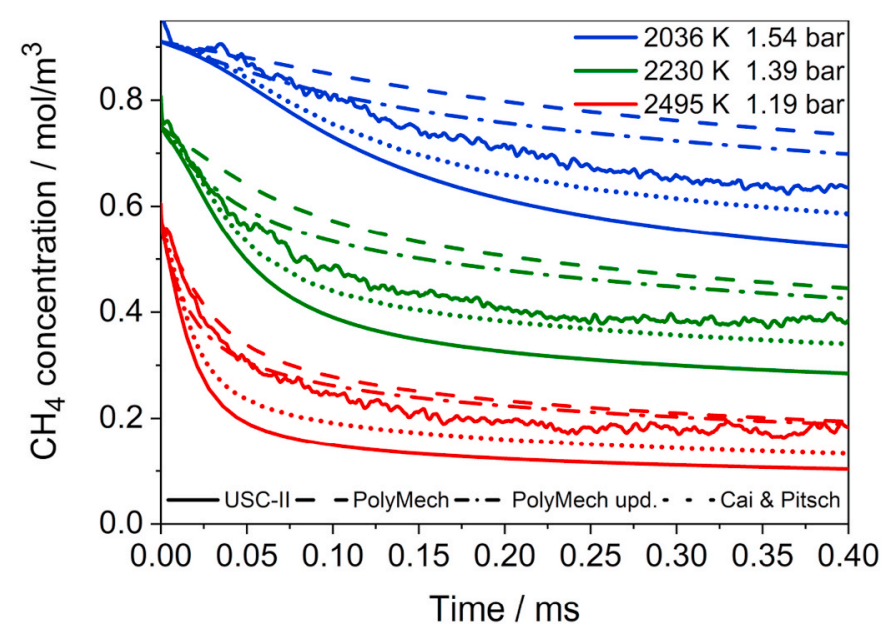

Fig. 23. Time-resolved $\mathrm{CH}_{4}$ concentration measurements (solid lines) during the pyrolysis of $10 \mathrm{~mol}_{\mathrm{C}} \mathrm{CH}_{4}$ in $\mathrm{Ar}$ in a shock tube. Simulations with USC-II ([64] (solid lines), PolyMech [23] (dashed lines), updated PolyMech (dash-dotted lines) and the Cai and Pitsch [33] mechanism (dotted lines).

\section{Experiments in engines}

\subsection{Product formation in the RCM}

In both the RCM and a single-cylinder research engine, experiments with mixtures of $\mathrm{CH}_{4}$ and DME were conducted over a wide range of equivalence ratios.

Because the RCM avoids some of the complexities of a reciprocating engine, results from these experiments are discussed first. Fig. 24 shows the product-gas species. At stoichiometric conditions $(\phi=1)$, the fuel components methane and DME are found only in small amounts in the product mixture. Since stoichiometric mixtures would be expected to undergo complete combustion, the $\mathrm{CH}_{4}$ and DME found in the product gas can be interpreted as residuals from wall quenching e.g., near the cylinder and piston top or in crevices. Only small amounts of $\mathrm{H}_{2}$ and $\mathrm{CO}$ are produced (Fig. 24a). $\mathrm{CO}_{2}$ is the main carbon-containing product (Fig. 24b), as seen from a carbon yield of nearly $100 \%$ for $\mathrm{CO}_{2}$. This is the "classical", nearly complete combustion process.

At $\phi=2$, the picture changes. Here, only $18 \%$ of the fuel carbon end up in $\mathrm{CO}_{2}$, but $70 \%$ in $\mathrm{CO}$. This strongly increased $\mathrm{CO}$ formation relative to $\phi=1$ is simply due to the fact that for a fuel-rich mixture complete combustion - in the sense of conversion to $\mathrm{H}_{2} \mathrm{O}$ and $\mathrm{CO}_{2}$ - is not possible anymore. The lack of oxygen at $\phi=2$ favors the formation of $\mathrm{CO}$. All other investigated species combined contain less than $2 \%$ of the fuel carbon. Similarly, the $\mathrm{H}_{2}$ yield increases relative to $\phi=1$. Note that also the fraction of $\mathrm{CH}_{4}$ in the product gas is now considerably higher than for $\varphi=1$. The carbon yield of $\mathrm{CH}_{4}$ increases from about $3 \%$ at $\phi=1$ to about $10 \%$ at $\phi=2$, i.e., by a factor of 3 . This is consistent with the notion that in addition to the wall quenching also observed at $\phi=1$, some fraction of the methane in the product gas is actually a genuine product of chemical reactions in the bulk gas. This is corroborated by the fact that the equilibrium composition of a $\mathrm{CH}_{4} / \mathrm{DME} /$ air mixture at $\phi=$ 2 contains several percent of $\mathrm{CH}_{4}$. Fig. 24a shows that the molar $\mathrm{H}_{2} / \mathrm{CO}$ ratio for $\phi=2$ is about 1.2.

At $\phi=6$ and 7, the product still contains more $\mathrm{H}_{2}$ than $\mathrm{CO}$. The latter now captures about $25 \%$ of the fuel carbon. There is also significant conversion into higher hydrocarbons, with $\mathrm{C}_{2} \mathrm{H}_{4}$ and $\mathrm{C}_{2} \mathrm{H}_{6}$ yields of almost $2 \%$ and about $0.75 \%$, respectively. When the equivalence ratio is increased further, the yields of $\mathrm{C}_{2} \mathrm{H}_{4}, \mathrm{C}_{2} \mathrm{H}_{2}$, and $\mathrm{H}_{2}$ decrease again. Of all investigated product species, only the methanol $\left(\mathrm{CH}_{3} \mathrm{OH}\right)$ yield increases for even richer mixtures. However, at $\phi=15$, only $0.3 \%$ of the fuel carbon is converted to $\mathrm{CH}_{3} \mathrm{OH}$ carbon, with that species presumably mainly originating from DME. More importantly, the formation of $\mathrm{C}_{2}$ 
(a)
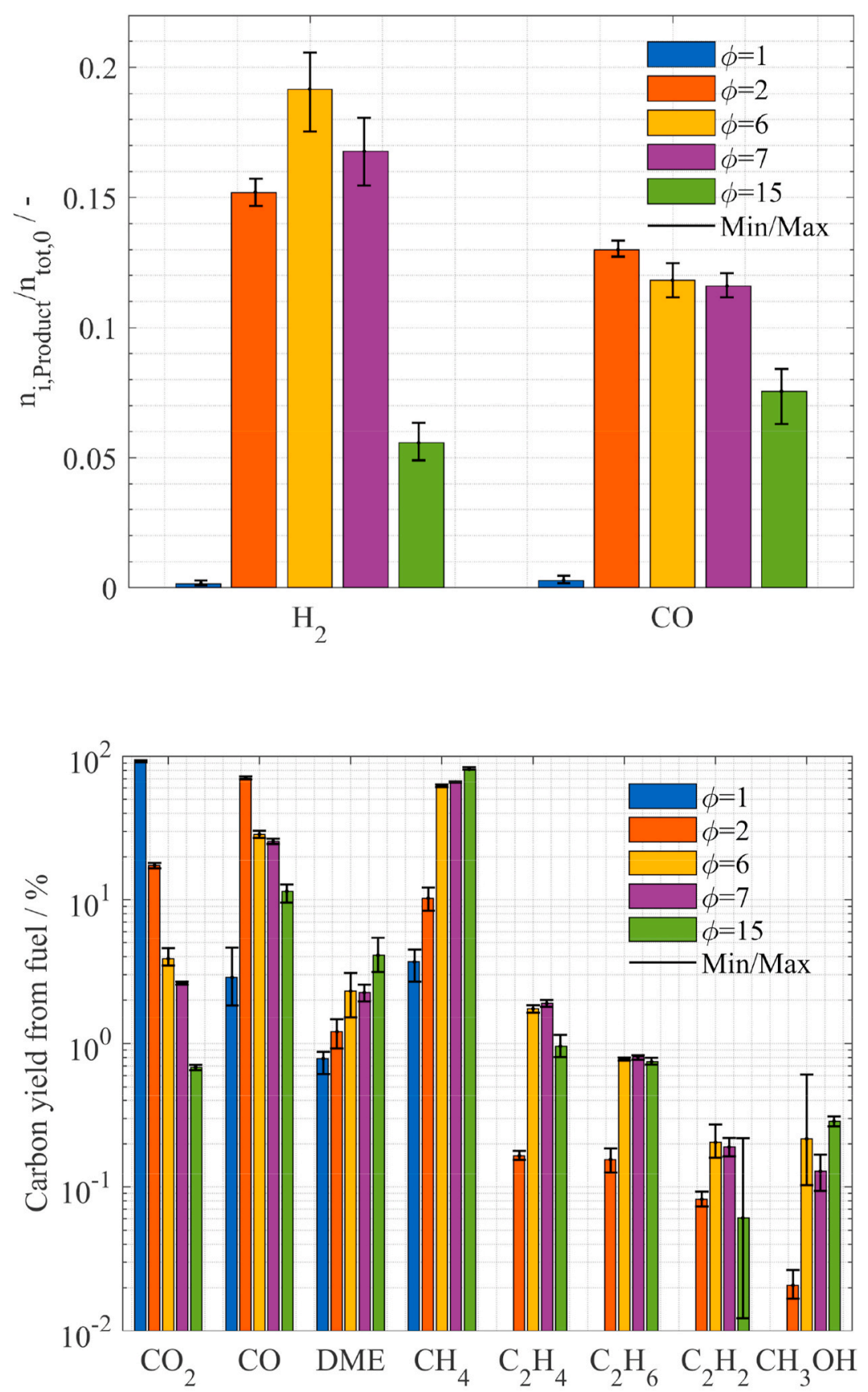

(b)

Fig. 24. Species production in the RCM from $\mathrm{CH}_{4} / \mathrm{DME}(90 / 10) /$ air mixtures over a wide range of equivalence ratios. (a) Total yields of $\mathrm{H}_{2}$ and $\mathrm{CO}$, defined as the molar amount of product divided by the initial total molar amount (sum over all species). (b) Carbon yield of the most important products. Compression temperature and pressure: $T=756-985 \mathrm{~K}, p=10$ bar. The error bars indicate the minimum and maximum values in the 6-9 repetitions of the experiment at each condition.

species is at least in the percent regime. Similar studies on dry reforming of methane described in Section 4.3 suggest that by systematic optimization (supported by numerical simulations), much higher yields should be possible. Fig. 24 also shows that by tuning the equivalence ratio the $\mathrm{H}_{2}$ /CO ratio can be varied, which may be of interest for further processing of syngas.

For basic research, the RCM allows much experimental freedom and control over the thermo-chemical conditions with well-defined initial and boundary conditions. However, in a reciprocating engine, further complexity arises, e.g., the coupling between successive cycles via the residual gas that remains in the cylinder after the exhaust stroke. Thus, experiments in an engine are reported next.

\subsection{Reciprocating engine}

The experiments were conducted in a single-cylinder engine that was originally designed for octane number testing of liquid fuels at compressions ratios between 4 and 10. It has $337 \mathrm{~cm}^{3}$ displacement volume and was run here at a speed of $600 \mathrm{rpm}$. The engine was modified to operate also with gaseous fuels and to reach compression ratios of up to 20. Gaseous and liquid fuels were metered into the (also metered) intake air and the mixture was preheated before it enters the intake. The crankangle resolved cylinder pressure was recorded, and in the product-gas stream the mole fractions of $\mathrm{O}_{2}, \mathrm{CH}_{4}, \mathrm{C}_{2} \mathrm{H}_{4}, \mathrm{CO}$, and $\mathrm{H}_{2}$ were measured by gas analyzers (ABB) in continuous on-line sampling. The 
soot content was measured as a filter smoke number by an AVL smoke meter and converted to a mass fraction. The product gases are poisonous and combustible, and since in the laboratory context there is no downstream processing, they were burned. More experimental details can be found in Refs. $[65,66]$.

\subsubsection{Operating stability}

Given the unusual intake compositions targeted here, the first concern was how HCCI operation could be achieved. Among other considerations, "good" engine operation requires that ignition occurs in every cycle, and that combustion is timed appropriately with respect to the kinematics of compression and expansion - if it is too early, the cylinder pressure increases very quickly, which can damage the engine, and if it is too late, the high-temperature chemistry is frozen before the desired chemical conversion can take place.

As expected, due to the low reactivity of methane, at compression ratios typical for spark-ignition engines (about 9-14), autoignition did not occur for any equivalence ratio. Adding a few percent ethane or propane to the methane - to yield a surrogate more representative of pipeline natural gas - did not change this situation. However, as discussed above, with more reactive additives like DME or DEE, HCCI operation is possible within a certain window of additive content in the fuel.

The basic procedure applied here for determining this operating window is a scan, in which the additive flow is systematically increased for a constant methane flow [65]. Two criteria for acceptable operation were chosen. The first criterion is a low coefficient of variation (CoV), a metric of cycle repeatability.

$\mathrm{CoV}=\frac{\sigma\left(\mathrm{IMEP}_{\text {net }}\right)}{\mathrm{IMEP}_{\text {net }}}$

where IMEP ${ }_{\text {net }}$ is the net indicated mean effective pressure defined as

$\mathrm{IMEP}_{\text {net }}=\mathrm{IMEP}-\mathrm{IMEP}_{\text {mot }}$

That is, at each operating point the indicated mean effective pressure (IMEP) was calculated from the pressure traces of 140 cycles, the IMEP $_{\text {mot }}$ from a motored cycle was then subtracted from each, and the standard deviation $\sigma$ was also estimated from that the resulting IMEP ${ }_{\text {net. }}$

The IMEP is directly linked to the indicated work $W$ per cycle and the swept volume $\Delta V$ :
$W=\operatorname{IMEP} \times \Delta V$

A CoV value of $10 \%$ was chosen as an upper limit for stable operation. The second criterion is the maximum pressure-rise rate ( $\left.P R R_{\max }\right)$, a metric for mechanical stress on piston, cylinder, and related components. It was measured with the in-cylinder pressure transducer and an upper limit of $10 \mathrm{bar} /{ }^{\circ} \mathrm{CA}$ was deemed acceptable.

Fig. 25 shows a scan for a constant methane flow with the DME flow varied. Across the scan, the overall equivalence ratio slightly changes, from $\phi=2.0$ at the lowest to 2.2 at the highest DME fraction. In addition

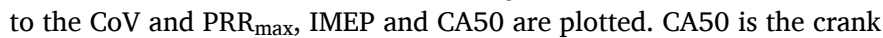
angle at which $50 \%$ of the heat release has taken place, a metric of combustion phasing, that is, how the chemical reactions are timed with respect to the kinematics of the engine cycle.

At low DME mole fractions, the mixture does not ignite, resulting in negative IMEP values. Adding more DME first leads to irregular firing and consequently to a high CoV. With increasing additive concentration, more cycles fire, and the CoV decreases while IMEP and $\mathrm{PRR}_{\max }$ increase. The non-monotonic behavior in these metrics at $x_{\mathrm{DME}}=$ $10-10.4 \%$ is associated with alternating firing and misfiring cycles due to the residual gas transferring unreacted or reacted mixture, respectively, from one cycle to the next. Increasing the intake additive fraction further induces stable engine operation at 10.5\% DME. With more additive, CA50 shifts early. This results in increasing $P_{R R}$ max because the heat is released at a smaller cylinder volume. The maximum IMEP is reached for the latest CA50 with stable engine operation, $16^{\circ} \mathrm{CA}$ after TDC. In modern engines with a more compact shape of the combustion chamber than this octane-number testing engine, the specific heat losses are lower and (for stoichiometric operation) typical CA50 at maximum IMEP are $3-8^{\circ} \mathrm{CA}$ after TDC. At $11.3 \%$ DME the $\mathrm{PRR}_{\max }$ reaches the 10 bar $/{ }^{\circ} \mathrm{CA}$ limit. Once the operating window was established, further experiments were performed with the lowest amount of additive that yielded stable operation - here, 10.5\% DME.

\subsubsection{Outputs and efficiencies}

Fig. 26 shows the species and energetic outputs from the engine as well as efficiencies over a wide range of equivalence ratios, from 0.5 to 12. The figure contains three groups of data points: spark ignition (SI) at lean, stoichiometric, and rich equivalence ratios, rich HCCI (with DME as an additive), and ultra-rich HCCI (with DEE). For $0.5<\phi<2.1$ the engine was operated in SI mode without any additive. Fig. 26 includes

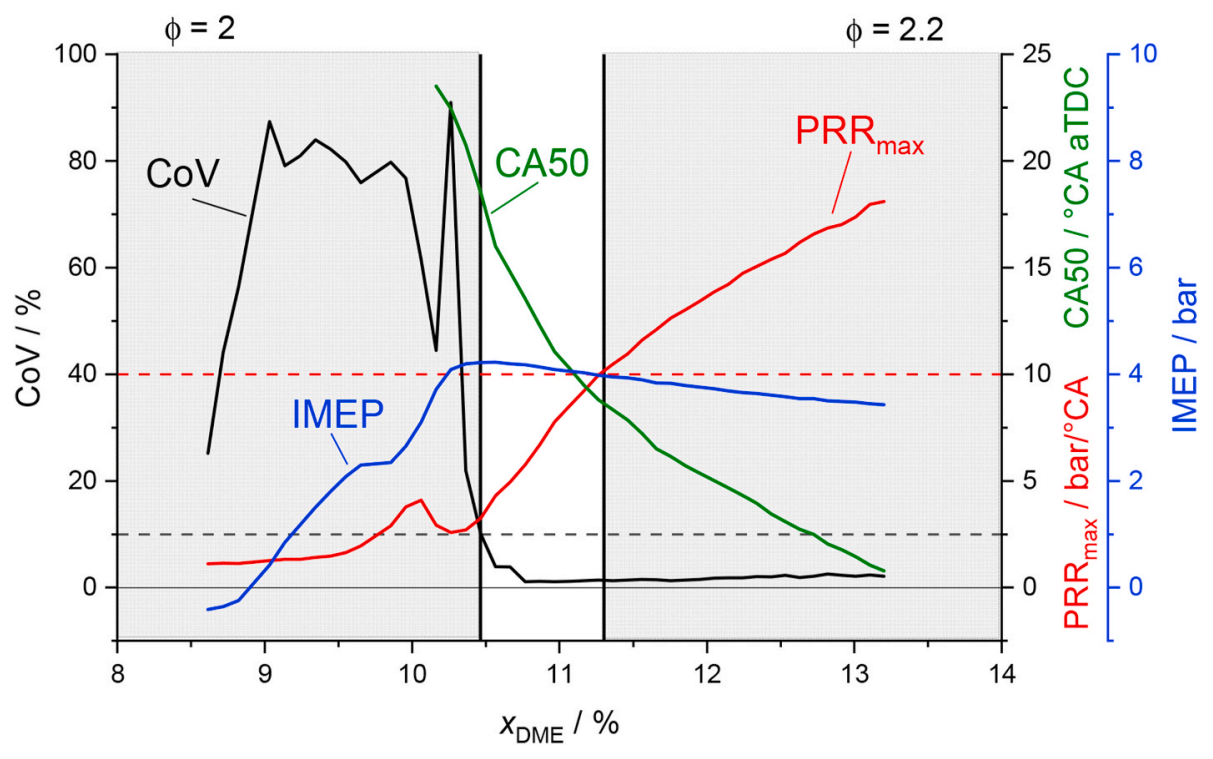

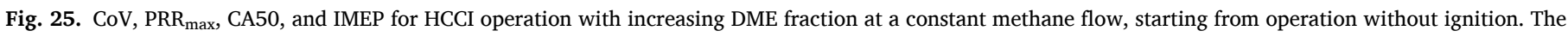
white region marks acceptable engine operation. The intake temperature was $T_{\mathrm{in}}=423 \mathrm{~K}$ and the compression ratio $\varepsilon=10$. 


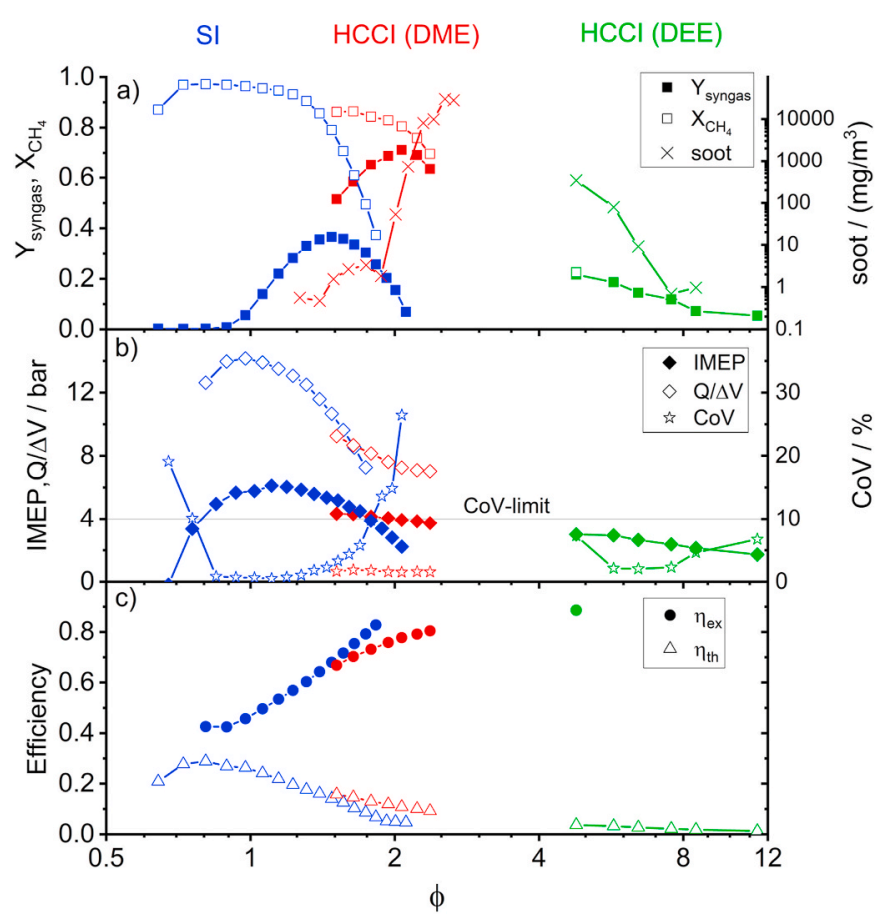

Fig. 26. a) Methane conversion $\left(X_{\mathrm{CH} 4}\right)$, syngas yield ( $Y_{\text {syngas }}$ ), and product-gas soot concentration (note the logarithmic scale), b) displacement-specific work (IMEP) and heat $(-Q / \Delta V)$ output of the engine as well as the coefficient of variation of the net IMEP $(\mathrm{CoV}), \mathrm{c})$ exergetic $\left(\eta_{\mathrm{ex}}\right)$ and thermal efficiencies $\left(\eta_{\mathrm{th}}\right)$, all as a function of equivalence ratio at $\varepsilon=10$. Spark-ignition experiments with $T_{\text {in }}=323 \mathrm{~K}$, HCCI experiments with $T_{\text {in }}=423 \mathrm{~K}$. Data were not recorded for $2.5<\phi<4$ to avoid excessive soot in the instruments. For $\phi>5$, the methane fraction in the product exceeded the sensor range and therefore, $Q, \eta_{\mathrm{ex}}, Y_{\text {syn }}$, and $X_{\mathrm{CH} 4}$ could not be determined. For very high $\mathrm{CoV}$ some of the performance metrics cannot be evaluated reliably and the corresponding data points have been suppressed.

some SI operating points with a CoV exceeding the $10 \%$ limit. In HCCI mode, DME was used as additive for $1.5<\phi<2.5$, but DEE for higher equivalence ratios, because the mass flow controller for (gaseous) DME did not allow sufficient flow rates, while the liquid DEE could be injected in higher quantities by a commercial port fuel injector.

As Fig. 26a shows, the highest methane conversions $X_{\mathrm{CH} 4}$ are achieved with SI for lean to stoichiometric equivalence ratios. For very lean equivalence ratios, operation is unstable and conversion decreases because of increasing numbers of misfires. The yield $\mathrm{Y}$ of syngas is nearly zero. This is the conventional regime of engine operation. For $\phi>1$, the methane conversion is lower, and a significant amount of syngas is produced, with the maximum in yield in SI mode at $\phi=1.5$. For higher equivalence ratios, the yield is lower because of frequent misfires.

Operating the engine in HCCI mode with additives allowed for stable operation at all equivalence ratios greater than 1.5 (see CoV in Fig. 26b). Towards stoichiometric conditions, operation is limited by high $P_{R R} R_{\max }$. The methane conversion is again decreasing with increasing equivalence ratio, but in this case mostly due to a lack of oxygen. For $\phi>1.5$ it is significantly higher than in SI mode because misfires do not occur with HCCI. In the latter mode, the maximum syngas yield is at about $\phi=2.1$. Increasing the equivalence ratio further decreases the syngas yield, even though the partial oxidation of methane to syngas is stoichiometric at more fuel-rich conditions ( $\phi=4$, reaction (3) in Table 1). Like in SI mode (not shown here), the soot concentration in the product gas is very low $\left(<10 \mathrm{mg} / \mathrm{m}^{3}\right)$ for equivalence ratios below $\phi=2$ but increases strongly for richer mixtures. In the range of $2.4<\phi<4$ no experiments were carried out to prevent damage to the instruments, and generally operation was limited to $\phi<2.1$. As the equivalence ratio increases beyond $\phi>4$, decreasing soot concentrations were measured, and beyond $\phi=7$ soot formation becomes again insignificant. This is likely because due the high heat capacity of these ultra-rich mixtures and the low heat release, the in-cylinder temperatures are too low for soot formation. The ultra-rich regime with $\phi>4$ is not interesting for syngas production, because the yield is low, but at $\phi=7$ the product gas contains about 1.5 vol $\%$ ethylene.

Fig. 26b shows heat and work production of the process. The maximum work and heat outputs are, as expected, at $\phi=1$. As with the syngas yield (Fig. 26a), HCCI yields better results at $\phi>1.5$ than SI because misfiring is avoided. The work output is positive at all investigated equivalence ratios. At $\phi=11.5$, with 2 bar IMEP it is still about $30 \%$ of the maximum at stoichiometric.

In Fig. 26c, the thermal and exergetic efficiencies are shown. The two metrics were calculated as

$\eta_{\mathrm{th}}=\frac{W}{\sum_{i} m_{i} \times h_{L, i}}$

$\eta_{\mathrm{ex}}=1-\frac{E_{l}}{\sum_{i} m_{i} \times e_{i}}$ with $E_{l}=T_{\mathrm{sur}} \times S_{\mathrm{irr}}$

where $h_{L, i}$ is the (specific) lower heating value and $e_{i}$ is the specific chemical exergy of each hydrocarbon species $i$ at the engine inlet. The exergy loss $E_{l}$ is the product of the surrounding temperature $T_{\text {sur }}$ and the irreversible entropy generation $S_{\text {irr }}$. The latter is determined from a first law and second law analysis as described in Ref. [66].

While the thermal efficiency counts only work as a useful output, the exergetic efficiency considers all outputs, in this case work, heat, and product gas. With $29 \%$, the thermal efficiency has its maximum at $\phi=$ 0.8 and decreases with increasing equivalence ratio. In contrast, the exergetic efficiency has its minimum value of $40 \%$ at lean equivalence ratios and increases to over $70 \%$ at $\phi>1.5$. However, when the methane conversion is low, as it is for unstable SI operation with frequent misfires and ultra-rich HCCI, the value of the exergetic efficiency as a figure of merit of the process is limited.

Overall, if syngas is the target chemical output, a good operating strategy would be HCCI at $\phi=1.9$. The syngas yield would be higher in slightly richer operation, but this is just lean enough to keep engine-out soot concentrations low. The engine runs very stably, the (indicated) work that could be used by other machinery in the plant is still half of its maximum, and the exergetic efficiency is $75 \%$. To put the latter number in context [2], gives the exergetic efficiency of the commonly used methane steam reforming as $63 \%$. Polygeneration based on solar collectors, providing electricity, heat, cooling, and desalinated water yields exergetic efficiencies up to $32 \%$ [67]. Other systems combining power cycles with methanol production or desalinization reach efficiencies up to $60 \%$ [68].

\subsubsection{Elevated compression ratios}

For a compression ratio of $\varepsilon=10$, relatively large quantities of additive (over 20 mass\%) are needed for stable fuel-rich HCCI operation. Higher temperatures towards the end of compression are one way of increasing the mixture reactivity with less additive. This could be achieved by increasing the compression ratio or the intake temperature, but the latter also increases heat losses and potentially the hardware costs, e. g., because more temperature-resistant materials are needed in the engine design. Fig. 27 shows the DME mole fraction required for stable engine operation (i.e., at the $\mathrm{CoV}$ limit) for compression ratios from $\varepsilon=$ 10 to 19 at intake temperatures of 423 and $323 \mathrm{~K}$ and equivalence ratios from $\phi=1.2$ to 2 .

Towards high equivalence ratios, excessive sooting above $\phi=2$ limits useful operation at all compression ratios, while high pressure-rise rates determine the limits towards lower equivalence ratios. For higher compression ratios this limit shifts to higher equivalence ratios because the cylinder volume during the reaction is smaller. There is only a weak dependency of the required DME mole fraction on equivalence ratio, but 


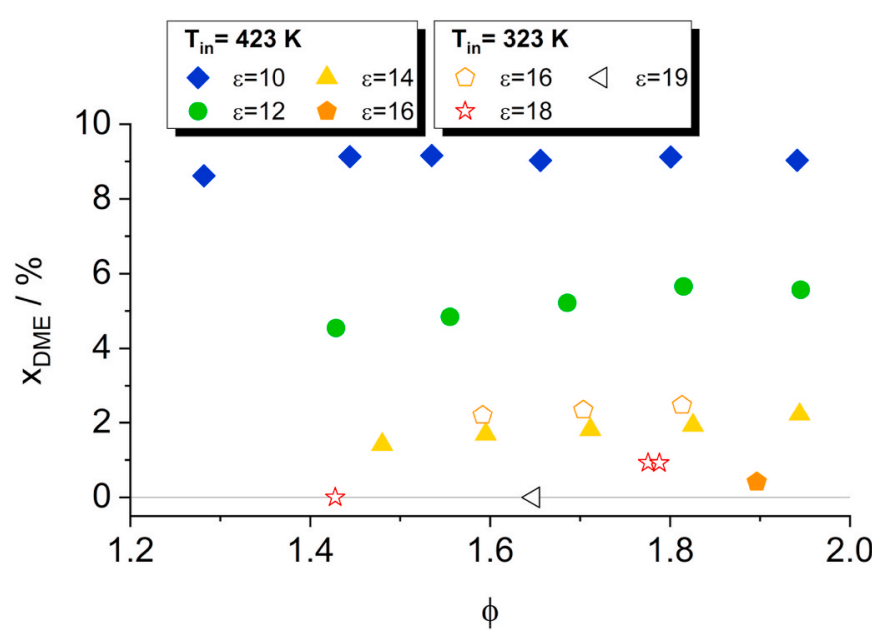

Fig. 27. DME mole fraction required for stable HCCI engine operation as a function of equivalence ratio for a range of compression ratios $\varepsilon$ and two different intake temperatures $T_{\text {in }}$.

a strong one on compression ratio. For an intake temperature of $423 \mathrm{~K}$, the required DME fraction decreases to less than 2 vol\% at $\varepsilon=14$. At $\varepsilon=$ 16 just $0.5 \%$ DME are needed, but only at $\phi=1.9$ stable, low-sooting operation without excessive pressure-rise rates could be established. Lowering the intake temperature to $323 \mathrm{~K}$ increases the additive demand but broadens the operating envelope in terms of $\phi$. Increasing the compression ratio to 18 and 19 enables acceptable operation without any DME addition at $\phi=1.42$ and 1.64, respectively. However, without additive, the remaining control parameters are intake temperature and equivalence ratio. Adjusting the former is slow, and the latter has little authority - both are known issues in "classic" lean HCCI. It may therefore be desirable to retain combustion control via a small fraction of an effective additive. For this purpose, ozone may be a promising candidate, as work on lean HCCI [69-72] has shown.

\subsection{Dry reforming: $\mathrm{CO}_{2}$ conversion with methane}

As a prospective application of chemical conversion in piston compressor devices, the dry reforming of methane with $\mathrm{CO}_{2}$ was investigated in an RCM [73]. The dry reforming process converts a $\mathrm{CO}_{2} / \mathrm{CH}_{4}$ mixture into syngas, according to the overall reaction (see Table 1)

$$
\mathrm{CH}_{4}+\mathrm{CO}_{2} \rightleftharpoons 2 \mathrm{CO}+2 \mathrm{H}_{2}
$$

This process offers a double benefit by both consuming $\mathrm{CO}_{2}$ and creating valuable chemical species.

As in the previous applications, conversion requires high temperatures due to the low reactivity of $\mathrm{CH}_{4}$ and $\mathrm{CO}_{2}$. With pure $\mathrm{CH}_{4} / \mathrm{CO}_{2}$ mixtures, it proves difficult to reach sufficiently high temperatures by compression, as discussed in Section 3.3. In addition to the measures discussed above - ignition promotors, dilution by monatomic gases -adding small amounts of oxygen to allow partially exothermal reactions may be considered here. A suitable combination of these strategies allows reaching good conversion levels.

Fig. 28 depicts simulated time histories of temperature and species during dry reforming of $\mathrm{CH}_{4}$ in an RCM. Two simulation approaches were taken. One is based on detailed chemistry, the other one is assuming that the system is always in chemical equilibrium at given (time-dependent) volume and internal energy. The initial mixture contains $\mathrm{CO}_{2}, \mathrm{CH}_{4}$, DME as reaction promoter, and also some oxygen. Compression starts after about $20 \mathrm{~ms}$, causing the initial temperature rise. Later, at about $70 \mathrm{~ms}$, chemical reactions commence, and one observes an additional temperature rise due to exothermal reactions. $\mathrm{CO}_{2}$ is reduced from $20 \mathrm{~mol} \%$ to $5 \mathrm{~mol} \%$ between 80 and $81 \mathrm{~ms}$. At about 82

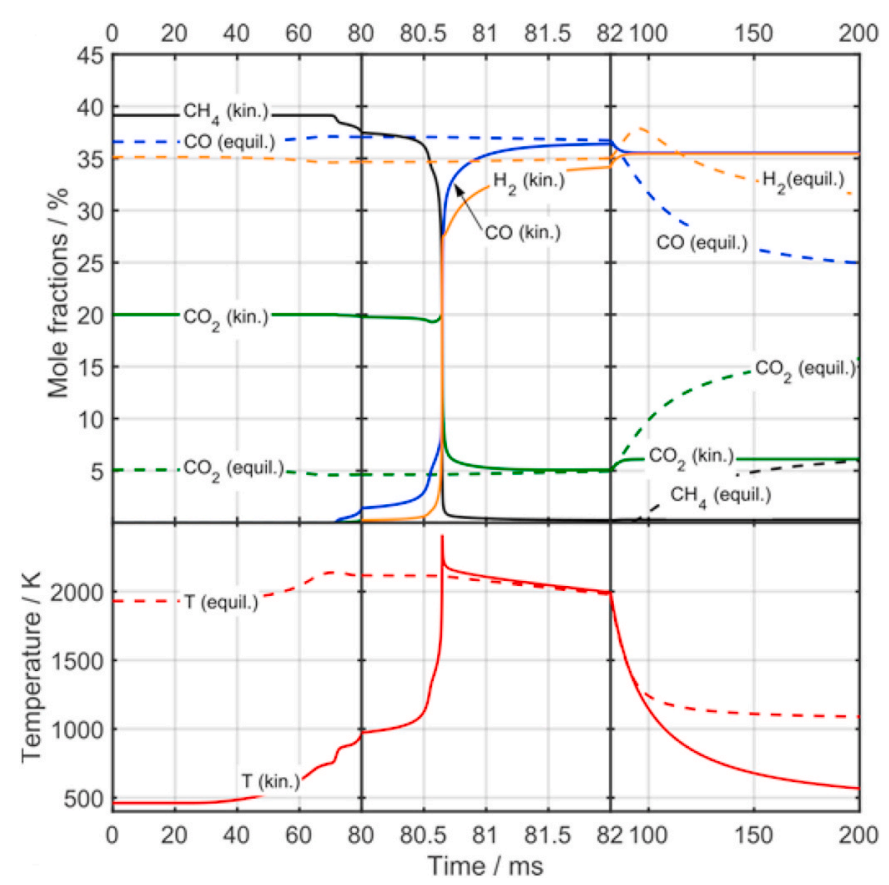

Fig. 28. Simulated temporal evolution of temperature and species during dry reforming in an RCM, with detailed chemistry (solid lines) and equilibrium chemistry (dashed lines). Compression starts at about 20 ms. Note the finer scaling of the time axis between 80 and $82 \mathrm{~ms}$.

$\mathrm{ms}$, the reactions have brought the system close to its equilibrium. If the reactions during the cool-down in the RCM were fast enough to keep the system in equilibrium, undesirable formation of $\mathrm{CO}_{2}$ would result (i.e., the rise of equilibrium $\mathrm{CO}_{2}$ after about $82 \mathrm{~ms}$ ). Finite-rate chemistry combined with a temperature drop due to heat losses and expansion helps keeping the system in a state of high $\mathrm{CO}_{2}$ conversion.

Mathematical optimization was used to identify a suitable initial composition [73], varying the gas composition among the species $\mathrm{Ar}$, $\mathrm{CH}_{4}, \mathrm{DME}, \mathrm{O}_{2}$, and $\mathrm{CO}_{2}$. For this, detailed chemistry simulations were carried out using an experimental volume profile from the RCM as a temporal constraint. The result is shown in Fig. 29. For initial $\mathrm{CO}_{2}$ mole fractions between 20 and $40 \%$, a conversion between 40 and $50 \%$ is predicted and is also found experimentally the experiments. In the RCM, some argon was added to increase the temperature after compression. This could be avoided with higher starting temperatures. The optimization approach was particularly helpful here in finding conditions that would have been substantially more difficult to find empirically. This kind of conversion could be a possible approach for carbon capture and use, e.g., if the energy required for compression can be taken from surplus work from renewable energies.

\section{Thermodynamic and economic assessment - a posteriori}

From the previous sections it is clear that a polygeneration process in a reciprocating IC engine is feasible, and that the exergetic efficiency considering only the engine with syngas, work, and heat as outputs is good. But at least two further issues must be addressed, the influence of all additional resources needed besides the engine on the efficiency of the process, and an overall economic assessment. A combination of thermodynamic and economic analysis is often performed with methods that are summarized e.g. in Refs. [74-77]. The exergoeconomic methods and values used here for the analysis of the polygeneration system are described in more detail in Ref. [78]. Such exergoeconomic analysis mainly facilitates comparing the economic importance of investment costs and exergy destruction and finding those parts of the process that are most crucial for cost reductions. Such an analysis was also carried 


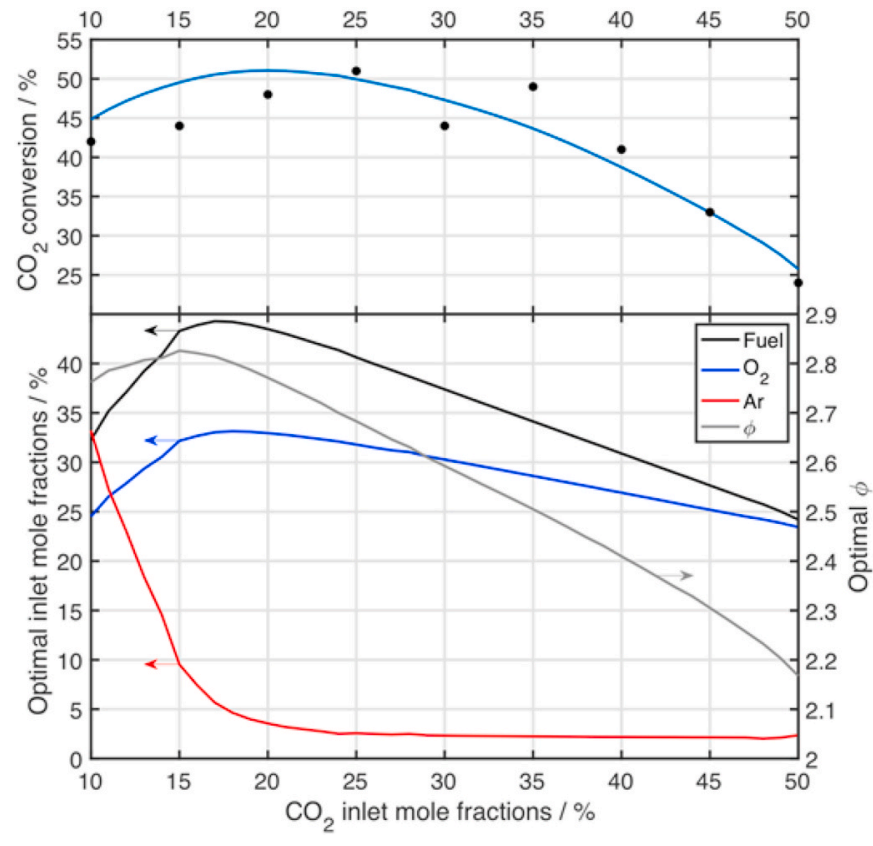

Fig. 29. Dry reforming in the RCM. Results of optimization for carbon dioxide conversion as a function of different initial carbon dioxide mole fractions. The predicted conversion is compared with experimental results in the upper part of the figure. The optimal initial compositions are shown in the lower part. Adapted from Ref. [73].

out for this system, but first the thermodynamic assessment has to be favorable.

For the thermodynamic assessment, the polygeneration system is compared with separate devices producing the same output of chemicals and work. The comparison from Refs. [79] is given in Table 2. It shows that a polygeneration $\mathrm{HCCI}$ engine with a displacement of $22.6 \mathrm{~L}$ reaches an exergetic efficiency of $79.2 \%$, which is higher than that of two separate processes selected according to the best values found in literature. Considering the engine only, exergy destruction mainly is due to the irreversibilities of the chemical reaction, and due to the heat flux through the wall. But in a complete system there may be other significant exergy losses. The product, although having a high exergy, consists of a mixture, including large amounts of $\mathrm{N}_{2}$. Thus, downstream product-gas separation must also be considered, as well as upstream conditioning of the reactants. As an example, a polygeneration system producing pure $\mathrm{H}_{2}$ as one of the material outputs was investigated [79]. In the model, the $\mathrm{H}_{2}$ separation was obtained with a noble-metal membrane, and the heat flows as well as the energy required for the

Table 2

Comparison of separate processes with the engine polygeneration process. (CHP: combined heat and power generation).

\begin{tabular}{|c|c|c|c|c|}
\hline Value & $\begin{array}{l}\text { IC } \\
\text { engine } \\
\text { CHP }\end{array}$ & $\begin{array}{l}\text { Steam methane } \\
\text { reforming }\end{array}$ & $\begin{array}{l}\text { HCCI engine } \\
\text { polygeneration, } \\
\text { engine only }\end{array}$ & $\begin{array}{l}\text { HCCI engine } \\
\text { polygeneration, } \\
\text { whole process }\end{array}$ \\
\hline Output & $\begin{array}{l}\text { Work, } \\
\text { heat }\end{array}$ & $\mathrm{H}_{2}$ & $\begin{array}{l}\text { Work, heat, } \\
\text { product gas }\end{array}$ & Work, heat, $\mathrm{H}_{2}$ \\
\hline$\phi$ & $<1$ & 0.97 & 2 & 2 \\
\hline$E$ & $\leq 47.3 \%$ & $62.7 \%$ & $79.2 \%$ & $59.4 \%$ \\
\hline \multirow[t]{2}{*}{ Costs } & $\begin{array}{l}\text { Work: } 3 \\
\text { ct/kWh }\end{array}$ & - & - & Work: $3.4 \mathrm{ct} / \mathrm{kWh}$ \\
\hline & - & $\mathrm{H}_{2}: 1.74 € / \mathrm{kg}$ & - & $\mathrm{H}_{2}: 1.75 € / \mathrm{kg}$ \\
\hline Ref. & {$[80]$} & $\begin{array}{l}\text { Klicken oder } \\
\text { tippen Sie hier, } \\
\text { um Text } \\
\text { einzugeben [2, } \\
81] \text {. }\end{array}$ & [82] & {$[82]$} \\
\hline
\end{tabular}

compressors were integrated into the system. Downstream of the engine, the $\mathrm{H}_{2}$ yield was increased in a water-gas shift reactor with heat integration. These additional process steps reduce the exergetic efficiency by $20 \%$-points to a more realistic exergetic efficiency of $59.4 \%$. This is similar to steam methane reforming but much higher than combined heat and power generation (CHP).

From an engineering point of view the process is favorable when the efficiency is high, while in practice the economics plays a crucial role: will the prices of the products be lower or at least similar to market prices? As part of an exergoeconomic analysis [78], the costs of the products were estimated using the investment costs via scaling laws, prices for methane, interest rates, lifetime of the unit, and other parameters. The resulting prices are also included in Table 2. The estimated prices for work are $13 \%$ higher than from a combined heat and power (CHP) plant, while the $\mathrm{H}_{2}$ costs are similar to large-scale steam methane reforming with an $\mathrm{H}_{2}$ output of $9000 \mathrm{~kg} / \mathrm{h}$, even though the output of the polygeneration system is much lower with $20.4 \mathrm{~kg} / \mathrm{h}$.

The resulting prices depend on the engine size and the economic parameters. The latter, for example unit lifetime, operating hours per year, prices for fuel and electricity, as well as the investment and installation costs of the 15 main components (engine, heat exchangers, compressors, membrane, etc.) are uncertain. Many are estimated based on current market prices that fluctuate considerably. Investments costs are interpolations from earlier compilations, as discussed in Ref. [78]. To evaluate the influence of these parameters on the costs of hydrogen, electricity, steam, and heat, a global sensitivity analysis was conducted [83] with an estimated relative uncertainty of $\pm 30 \%$ of each parameter [84]. A complete list of the parameters that were varied can be found in Refs. [78] (Table 3 and A3), but in the current work the capital investment values differ, because the engine size is different. From several ten thousands of calculations with a Monte-Carlo based design, where the costs and further parameters are varied according to a probability distribution within their uncertainty ranges, a distribution of hydrogen costs is obtained. The resulting cost distributions for hydrogen and total cost rates are shown in Fig. 30. The cost rate, which includes all outputs (hydrogen, work, and heat) shows that the hydrogen costs are about $70 \%$ of the total costs. Thus, all outputs are important from an economic point of view. Due to nonlinear relations between the economic parameters and the resulting prices, the most probable $\mathrm{H}_{2}$ price (the mean value) is $1.9 € / \mathrm{kg}$, which is higher than the price calculated with the initially estimated prices without variation, while the price distribution ranges from 1.2 to $2.9 € / \mathrm{kg}$.

Such a sensitivity analysis with a probability distribution gives a

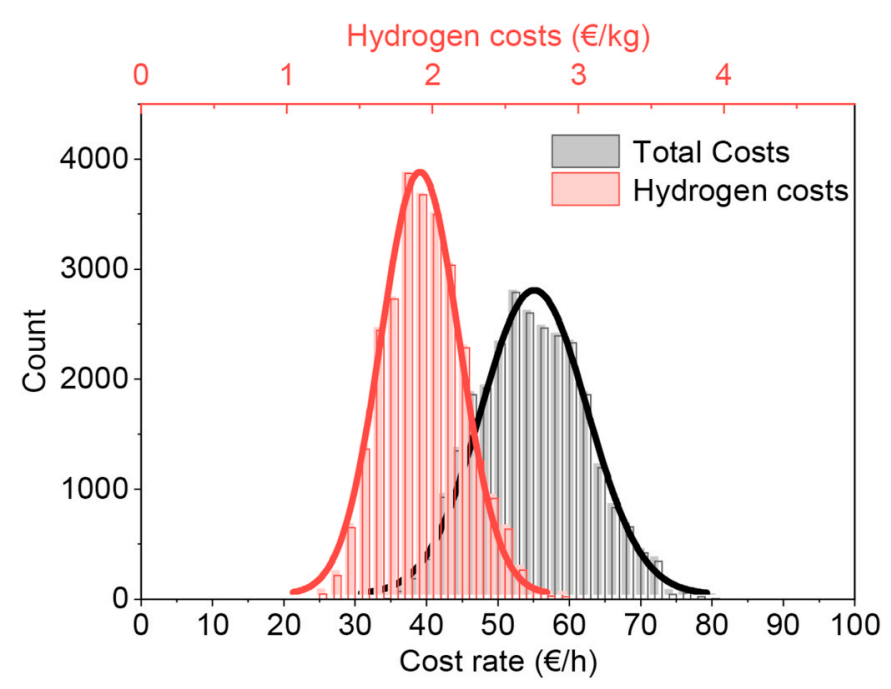

Fig. 30. Distribution of the hydrogen cost rates and total cost rates in $€ / \mathrm{h}$ for an uncertainty range of $\pm 30 \%$. The top $x$-axis translates the hydrogen cost rate into specific hydrogen costs in $€ / \mathrm{kg}$ [82]. 
good impression of the influence of each parameter and its uncertainties on the outcome. The first-order sensitivity coefficients agree well with the total sensitivities, indicating that higher-order sensitivities are negligible. The six highest sensitivity coefficients are listed in Table 3 for two different engine sizes. All other parameters influence the $\mathrm{H}_{2}$ price only to a minor degree. For the smaller engine size, the hydrogen cost is mainly sensitive to the operating hours per year, the noble-metal membrane costs, and the lifetime, while the fuel costs are less important. This changes with engines size and the higher throughput. Now the methane costs are crucial for the $\mathrm{H}_{2}$ price, followed by the membrane costs. This also indicates that to reduce the hydrogen costs, in future work alternatives to membrane separation should be considered, such as pressure-swing adsorption or membranes from lower-cost materials.

Also, the engine size could be further increased towards the size of large stationary engines or maritime diesel engines (sizes of 150-2000 $\mathrm{L} /$ cylinder are in operation today), which would probably reduce the sensitivity of the $\mathrm{H}_{2}$ cost on the investments and lifetimes further. However, for some of the engines the process would have to be modified due to the lower engine speeds.

\section{Conclusions and future work}

\subsection{Approach}

The methods and knowledge of combustion science can be used successfully towards the co-generation of useful chemicals in piston engines. The coordinated interplay of thermodynamic pre-assessment followed by a preliminary kinetic investigation with known but not yet validated models gives good and relatively fast insight into whether a certain system is worth further efforts and helps identifying the challenges. Here, it was helpful to start with simple and idealized models, for example assuming an adiabatic process with a homogeneous charge, initially neglecting the effects of residual gases. Thereby it was learned that the process could in fact be thermodynamically favorable, and which initial temperatures, compression ratios, and additive concentrations should be used as an experimental starting point. But caution is warranted because of the idealizations and lack of validation for some of the models. Therefore, in a next step the kinetics on various time scales were explored and product distributions were determined. Many reaction mechanisms were mainly developed and optimized to predict ignition delay times and flame speeds, while the product formation is only relevant for certain pollutants, but not for many major species that might be useful chemicals. Thus, the mechanisms had to be expanded using the established models as basis. This new mechanism then needs to be validated and improved. Here, three experimental facilities complemented each other to provide data over a large range of temperatures and thus time scales. The flow reactor covers the longest time scales and the lowest temperatures, while the shock tube is limited in its longest reaction time but can reach any practically useful temperature. The RCM is in between.

RCMs can also be considered the next step in complexity towards the application. These machines, while emulating the transient pressure and

\section{Table 3}

First-order and total sensitivity indices for the most important input parameters resulting from the sensitivity analysis of the hydrogen costs. (InC=Investment Costs).

\begin{tabular}{|c|c|c|c|c|}
\hline \multirow{2}{*}{$\begin{array}{l}\text { Engine displacement } \\
\text { Sensitivity index }\end{array}$} & \multicolumn{2}{|l|}{$1.6 \mathrm{~L}$} & \multicolumn{2}{|l|}{$22.6 \mathrm{~L}$} \\
\hline & $\mathrm{S}_{1}$ & $\mathrm{~S}_{\mathrm{T}}$ & $\mathrm{S}_{1}$ & $\mathrm{~S}_{\mathrm{T}}$ \\
\hline Fuel costs & 0.076 & 0.072 & 0.419 & 0.412 \\
\hline Operating hours & 0.306 & 0.327 & 0.196 & 0.209 \\
\hline InC membrane & 0.249 & 0.252 & 0.162 & 0.164 \\
\hline Interest rate & 0.193 & 0.192 & 0.123 & 0.123 \\
\hline Lifetime & 0.124 & 0.128 & 0.079 & 0.082 \\
\hline InC engine & 0.030 & 0.035 & 0.010 & 0.015 \\
\hline
\end{tabular}

temperature of a reciprocating engine, retain certain idealizations. For instance, it is relatively easy to do RCM experiments with well-defined initial conditions with respect to mixture composition, temperature, and pressure. RCMs can therefore bridge the gap between chemical kinetics studies and reciprocating engines. In addition, these experiments can identify promising additives or operating conditions for the production of specific species. Also, conditions with strong soot formation were identified, which in general should be avoided in reciprocating engines. However, the time until the mixture is analyzed in an RCM is relatively long and reactions continue on this timescale. In particular the slow reactions leading to soot formation may be overemphasized. Finally, even though they are much effort and, in some respect, provide less details, experiments in reciprocating engines must be performed, because many practical limitations are only seen in such experiments. Nevertheless, with the insight from the other methods, the engine experiments lead to faster success, and they can be understood in much more detail. The limits with respect to pressure rise rates, stable ignition (COV), and soot formation are best evaluated in the engine itself. This provides data not only on realistic product yields, but also on exergetic efficiency. From there, the process assessment needs to be expanded by including product separation and an overall thermodynamic and economic analysis with realistic error estimates from a global sensitivity analysis. Here, this was done via exergoeconomic modeling, since experiments on a systems level were beyond the scope of the investigation.

\subsection{Main results}

The initial gas composition, in particular the equivalence ratio $\phi$, is the most important influence on the product-gas composition. The yields of the target species, i.e., $\mathrm{H}_{2} / \mathrm{CO}, \mathrm{C}_{2} \mathrm{H}_{4}$, also showed a pronounced temperature dependence. Hence, favorable conditions for the production of chemicals in engines requires significant preheating. If preheating is not an option, then fuel additives can be used to promote ignition. To this end, DME (dimethylether, up to $10 \%$ of the fuel) was used. However, to reduce the additive fraction, finding alternatives to DME as a fuel additive seems essential for the production of useful products in an engine. A promising candidate is ozone, since it does not compete with the $\mathrm{CH}_{4}$ as a carbon source and can be produced from air with relatively low energy input [85].

The conversion of methane to synthesis gas with work and heat output can be established at equivalence ratios below 2, with an engine running stably in HCCI mode without significant soot formation. The yields of small hydrocarbons are low at these conditions. Better yields of higher hydrocarbons can be achieved at higher equivalence ratios, but soot formation is a problem at equivalence ratios between 2 and 4, while increasing the equivalence ratio further restricts the methane conversion. But this could perhaps be optimized.

A comparison of experiments and simulations with different literature oxidation mechanisms for fuel-rich mixtures (from $\phi=2$ to $\infty$ ) showed that these mechanisms can often predict the measured ignition delay times well, even for $\phi=10$. The product formation at $\phi=2$ (mostly syngas) can also be predicted well by several mechanisms, but most cannot predict the product formation at $\phi=10$ correctly for methane and natural-gas pyrolysis. This is not surprising, because these mechanisms were developed and validated for oxidation at lean and stoichiometric conditions, and therefore often do not contain benzene and PAH formation chemistry. Thus, especially acetylene and benzene mole fractions cannot be predicted well. An exception is the mechanism of Cai and Pitsch [33] that contains sufficiently detailed benzene and PAH chemistry.

However, this mechanism can be used only for $n$-heptane as the additive because it does not contain the chemistry of ethers like DME and DEE. Therefore, the development of a mechanism for $\mathrm{CH}_{4} / \mathrm{DME}$ mixtures ("PolyMech") was necessary to be able to predict both IDT and product concentrations. The experimental results obtained here were used as validation targets during the development. Deficiencies of 
PolyMech were detected and corrected by comparisons of experimental results and simulations. After including improved rate coefficients for $\mathrm{CH}_{4}+\mathrm{M}=\mathrm{CH}_{3}+\mathrm{H}$ [58] and $\mathrm{CO}+\mathrm{HO}_{2}=\mathrm{CO}_{2}+\mathrm{OH}$ [54], PolyMech now seems to be useful over a wide range of equivalence ratios, including reactant mixtures with oxygenates, but is yet to be validated at stoichiometric and lean conditions. Benzene consumption reactions have to be added in the future.

A mathematical model based on timescales and entropy-production analysis was proposed for the reduction of high-dimensional reaction mechanisms. The results of local and global time scale analysis for PolyMech were used to find an optimal reduced-model dimension. Invariant sub-spaces of the linearization matrices allowed formulating the reduced model in the decomposed form (as a DEA), while entropy production was further employed to identify key reactions and to construct reliable skeletal mechanisms.

Experiments in the RCM and single-zone simulations of endothermal methane pyrolysis and dry reformation of $\mathrm{CO}_{2}$ with methane (forming syngas) showed that work can efficiently be used for chemical conversion. However, the efficiency strongly and nonlinearly depends on the initial and boundary conditions. This, together with the large number of relevant conditions (initial temperature, pressure, mixture composition, compression parameters like compression ratio and speed and expansion) makes finding good operation conditions difficult. A combination of experiments with numerical simulations was demonstrated that allows a systematic optimization of the process.

The exergetic efficiency of polygeneration in the IC engine reaches values of up to $79.2 \%$, which is very high. With upstream reactant conditioning and downstream product separation considered, the efficiency of the polygeneration decreases to a still reasonable $59.4 \%$ and is thus similar to steam reforming and much better than heat-power cogeneration. Work and hydrogen can be provided at competitive costs if larger engines are used.

In experiments in a single-cylinder engine with a compression ratio $\varepsilon$ $=10$, stable HCCI operation with acceptable pressure-rise rates could be established for equivalence ratios in the range of $1.5<\phi<12$. Soot formation can be avoided for $\phi<2$ and $\phi>7$. The maximum syngas yield in the soot-free regime is $69 \%$ at $\phi=1.9$. Operation at $\phi=7$ yielded $1.5 \%$ ethylene in the product gas. However, energetically significant fractions of ignition-promoters like DME or DEE had to be added to the methane fuel. Increasing the compression ratio enables stable operation with much decreased additive demand. At $\varepsilon=18$ and 19 operation without any additive could be achieved.

Finally, an economic assessment was performed for one exemplary system. It turns out that a global sensitivity analysis is most helpful for at least two reasons: First, the most critical parameters for cost reduction are easily found. In the investigated example, besides parameters like operating hours or fuel costs, in terms of plant design it was the gas separation for which alternative methods should be investigated. Second, it is found that the most probable costs are not the same as the costs calculated with the most probable parameters, due to the nonlinear dependence between input parameters and product costs.

\subsection{Open questions and future directions}

Having found that this process is promising in general, future directions can be considered. On one hand, more specific questions have to be addressed that were not part of the initial investigation. On the other, a further generalization towards different gas-phase conversions seems interesting.

For example, the inhomogeneity in the engine is neglected so far, including the flow field. This can be addressed to obtain information about better engine geometries and higher yields for some conditions. Also, more complex valve timings, multiple fuel injections, or different additives appear promising. In-cylinder catalysts, e.g. porous materials in part of the combustion chamber, may reduce conversion temperatures, but would probably be transport-limited and may increase wall heat losses. Nevertheless, a more systematic investigation would be interesting. Any increase in complexity will benefit from mathematical optimizations.

The initial motivation of the work presented here on dry reforming of $\mathrm{CH}_{4}$ with $\mathrm{CO}_{2}$ was to find a process that allows storing energy via an endothermal reaction. However, since oxygen burns part of the fuel, energy is not as effectively stored as possible, despite the net conversion of $\mathrm{CO}_{2}$. Oxygen was used in the experiments to attain higher temperatures during compression, since the RCM had a maximum compression ratio of approximately 10 , and the maximum initial temperature was $462 \mathrm{~K}$. These two aspects limit the maximum temperature attainable by compression work alone. For an energy storage process, future work will need to focus on whether dry reforming can be carried out without associated combustion. This probably requires more preheating or different additives.

For industrial applications upscaling will be needed. A good medium-size target may be wastewater treatment plants, where offgases containing mostly methane and $\mathrm{CO}_{2}$ are produced and syngas products like methanol are needed for feeding the microorganisms. Also, an engine polygeneration process has been investigated for converting flare gases from off-grid oil wells into more easily transportable liquids [15]. On a larger scale, industrial syngas plants produce on the order of 100000 standard cubic meters per hour $\left(\mathrm{m}_{S}^{3} / \mathrm{h}\right)$ of dry syngas. The experimental results in Section 4.2 showed a syngas $\left(\mathrm{CO}+\mathrm{H}_{2}\right)$ output of $1.24 \mathrm{~m}_{\mathrm{S}}^{3} / \mathrm{h}$ for an engine with $0.337 \mathrm{~L}$ displacement operating at $1 \mathrm{bar}$ intake pressure and $600 \mathrm{rpm}$, while the IMEP was 4.4 bar. A more common operating condition for a large four-stroke engine would be $1500 \mathrm{rpm}$ with turbocharging to an intake pressure of $3 \mathrm{bar}$. Assuming that the output of the HCCI process scales up linearly in engine speed and intake pressure, this kind of engine would produce $27.6 \mathrm{~m}_{\mathrm{S}}^{3} / \mathrm{h}$ per liter of engine displacement, and 13.2 bar IMEP. Large commercially available combined heat-power plants have displacements on the order of $100 \mathrm{~L}$. Thus, about 37 of such plants would be needed for 100000 $\mathrm{m}_{\mathrm{S}}^{3} / \mathrm{h}$ of syngas. Some of the mechanical power output could be used for downstream gas separation, as discussed in Ref. [79]. Among the issues that will need to be addressed before practical implementation is long-term durability of the engine under such unusual operating conditions.

Beyond the conversion of hydrocarbons including biofuels, there are very different energy storage systems including nitrogen or sulfur oxides. It may be worth studying whether polygeneration in a piston engine may be favorable for some of these processes from a thermodynamic, kinetic, and finally an economic point of view.

\section{CRediT authorship contribution statement}

Burak Atakan: Conceptualization, Methodology, Writing - original draft, Supervision, Project administration, Funding acquisition. Sebastian A. Kaiser: Conceptualization, Methodology, Writing - original draft, Supervision, Project administration, Funding acquisition. Jürgen Herzler: Methodology, Writing - original draft, Investigation. Sylvia Porras: Investigation, Writing - original draft, Methodology. Kai Banke: Investigation, Writing - original draft, Methodology. Olaf Deutschmann: Conceptualization, Methodology, Supervision, Project administration, Funding acquisition. Tina Kasper: Conceptualization, Methodology, Supervision, Project administration, Funding acquisition, Writing - review \& editing. Mustapha Fikri: Supervision, Project administration, Funding acquisition. Robert Schießl: Supervision, Project administration, Funding acquisition, Writing - review \& editing. Dominik Schröder: Investigation, Writing - original draft, Methodology. Charlotte Rudolph: Investigation, Writing - original draft, Methodology. Dennis Kaczmarek: Investigation, Writing - original draft, Methodology. Hendrik Gossler: Investigation, Writing - original draft, Methodology. Simon Drost: Investigation. Viatcheslav Bykov: Investigation, Methodology. Ulrich Maas: Conceptualization, Methodology, Supervision, Project administration, Funding acquisition. Christof 
Schulz: Conceptualization, Methodology, Writing - original draft, Supervision, Project administration, Funding acquisition.

\section{Declaration of competing interest}

The authors declare that they have no known competing financial interests or personal relationships that could have appeared to influence the work reported in this paper.

\section{Acknowledgements}

This work was supported by the Deutsche Forschungsgemeinschaft, DFG, within the Research Unit FOR 1993 'Multi-functional conversion of chemical species and energy', grant 229243862.

\section{References}

[1] acatech - National Academy of Science and Engineering. Coupling the different energy sectors - options for the next phase of the energy transition. Acatech; 2018 ISBN: 978-3-8047-3673-3.

[2] Simpson Adam P, Lutz Andrew E. Exergy analysis of hydrogen production via steam methane reforming. Int J Hydrogen Energy 2007;32(18):4811-20. https:/ doi.org/10.1016/j.ijhydene.2007.08.025.

[3] Li H, Hong H, Jin H, Cai R. Analysis of a feasible polygeneration system for power and methanol production taking natural gas and biomass as materials. Appl Energy 2010;87(9):2846-53. https://doi.org/10.1016/j.apenergy.2009.07.001.

[4] Jana K, Ray A, Majoumerd MM, Assadi M, De S. Polygeneration as a future sustainable energy solution - a comprehensive review. Appl Energy 2017;202: 88-111. https://doi.org/10.1016/j.apenergy.2017.05.129.

[5] Liu G-j, Li Z, Wang M-h, Ni W-d. Energy savings by co-production: a methanol/ electricity case study. Appl Energy 2010;87(9):2854-9. https://doi.org/10.1016/j apenergy.2009.08.036.

[6] Khojasteh Salkuyeh Y, Adams TA. Integrated petroleum coke and natural gas polygeneration process with zero carbon emissions. Energy 2015;91:479-90. https://doi.org/10.1016/j.energy.2015.08.056.

[7] Khojasteh Salkuyeh Y, Adams TA. A novel polygeneration process to co-produce ethylene and electricity from shale gas with zero $\mathrm{CO} 2$ emissions via methane oxidative coupling. Energy Convers Manag 2015;92:406-20. https://doi.org/ 10.1016/j.enconman.2014.12.081.

[8] Tartakovsky L, Sheintuch M. Fuel reforming in internal combustion engines. Prog Energy Combust Sci 2018;67:88-114. https://doi.org/10.1016/j. pecs.2018.02.003.

[9] Eyal A, Tartakovsky L. Second-law analysis of the reforming-controlled compression ignition. Appl Energy 2020;263:114622. https://doi.org/10.1016/j. apenergy.2020.114622.

[10] Chuahy FDF, Kokjohn SL. High efficiency dual-fuel combustion through thermochemical recovery and diesel reforming. Appl Energy 2017;195:503-22. https://doi.org/10.1016/j.apenergy.2017.03.078.

[11] Hunicz J, Mikulski M, Geca MS, Rybak A. An applicable approach to mitigate pressure rise rate in an HCCI engine with negative valve overlap. Appl Energy 2020;257:114018. https://doi.org/10.1016/j.apenergy.2019.114018.

[12] Peucheret S, Wyszynski M, Lehrle R, Golunski S, Xu H. Use of catalytic reforming to aid natural gas HCCI combustion in engines: experimental and modelling results of open-loop fuel reforming. Int J Hydrogen Energy 2005;30(15):1583-94. https:// doi.org/10.1016/j.ijhydene.2005.02.001.

[13] Szeszich L von. Herstellung von Synthesegas im Otto-Motor bei gleichzeitiger Arbeitsgewinnung. Chem Ing Tech 1956;28(3):190-5. https://doi.org/10.1002/ cite.330280310.

[14] McMillian M, Lawson S. Experimental and modeling study of hydrogen/syngas production and particulate emissions from a natural gas-fueled partial oxidation engine. Int J Hydrogen Energy 2006;31(7):847-60. https://doi.org/10.1016/j. ijhydene.2005.08.013.

[15] Lim EG, Dames EE, Cedrone KD, Acocella AJ, Needham TR, Arce A, et al. The engine reformer: syngas production in an engine for compact gas-to-liquids synthesis. Can J Chem Eng 2016;94(4):623-35. https://doi.org/10.1002/ cjce. 22443.

[16] Karim GA, Moore NPW. Examination of Rich mixture operation in a dual fuel engine. SAE technical paper 9015001990.

[17] Fischer SL, Dryer FL, Curran HJ. The reaction kinetics of dimethyl ether. I: hightemperature pyrolysis and oxidation in flow reactors. Int J Chem Kinet 2000;32 (12):713-40. https://doi.org/10.1002/1097-4601(2000)32:12<713:AIDKIN1>3.0.CO;2-9.

[18] Zhao Z, Chaos M, Kazakov A, Dryer FL. Thermal decomposition reaction and a comprehensive kinetic model of dimethyl ether. Int J Chem Kinet 2008;40(1):1-18 https://doi.org/10.1002/kin.20285.

[19] Prince JC, Williams FA. A short reaction mechanism for the combustion of dimethyl-ether. Combust Flame 2015;162(10):3589-95. https://doi.org/10.1016/ j.combustflame.2015.06.016.

[20] Burke U, Somers KP, O'Toole P, Zinner CM, Marquet N, Bourque G, et al. An ignition delay and kinetic modeling study of methane, dimethyl ether, and their mixtures at high pressures. Combust Flame 2015;162(2):315-30. https://doi.org/ 10.1016/j.combustflame.2014.08.014.

[21] Li Y, Zhou C-W, Somers KP, Zhang K, Curran HJ. The oxidation of 2-butene: a high pressure ignition delay, kinetic modeling study and reactivity comparison with isobutene and 1-butene. Proc Combust Inst 2017;36(1):403-11. https://doi.org/ 10.1016/j.proci.2016.05.052.

[22] Zhou C-W, Li Y, Burke U, Banyon C, Somers KP, Ding S, et al. An experimental and chemical kinetic modeling study of 1,3-butadiene combustion: ignition delay time and laminar flame speed measurements. Combust Flame 2018;197:423-38. https://doi.org/10.1016/j.combustflame.2018.08.006.

[23] Porras S, Kaczmarek D, Herzler J, Drost S, Werler M, Kasper T, et al. An experimental and modeling study on the reactivity of extremely fuel-rich methane/ dimethyl ether mixtures. Combust Flame 2020;212:107-22. https://doi.org/ 10.1016/j.combustflame.2019.09.036.

[24] Atakan B. Gas turbines for polygeneration? A thermodynamic investigation of a fuel rich gas turbine cycle. Int J Therm 2011;14(4):185-92.

[25] McBride BJ, Zehe MJ, Gordon S. NASA glenn coefficients for calculating thermodynamic properties of individual species. 2002.

[26] Herzler J, Sakai Y, Fikri M, Schulz C. Shock-tube study of the ignition and product formation of fuel-rich $\mathrm{CH} 4$ /air and $\mathrm{CH} 4$ /additive/air mixtures at high pressure. Proc Combust Inst 2019;37(4):5705-13. https://doi.org/10.1016/j. proci.2018.05.120.

[27] Werler M, Cancino LR, Schiessl R, Maas U, Schulz C, Fikri M. Ignition delay times of diethyl ether measured in a high-pressure shock tube and a rapid compression machine. Proc Combust Inst 2015;35(1):259-66. https://doi.org/10.1016/j. proci.2014.06.143.

[28] Drost S, Schießl R, Werler M, Sommerer J, Maas U. Ignition delay times of polyoxymethylene dimethyl ether fuels (OME2 and OME3) and air: measurements in a rapid compression machine. Fuel 2019;258:116070. https://doi.org/10.1016/ j.fuel.2019.116070.

[29] Rasmussen CL, Hansen J, Marshall P, Glarborg P. Experimental measurements and kinetic modeling of $\mathrm{CO} / \mathrm{H} \mathrm{2/O} \mathrm{2/NO} \mathrm{x} \mathrm{conversion} \mathrm{at} \mathrm{high} \mathrm{pressure.} \mathrm{Int} \mathrm{J}$ Chem Kinet 2008;40(8):454-80. https://doi.org/10.1002/kin.20327.

[30] Chen Z, Qin X, Ju Y, Zhao Z, Chaos M, Dryer FL. High temperature ignition and combustion enhancement by dimethyl ether addition to methane-air mixtures. Proc Combust Inst 2007;31(1):1215-22. https://doi.org/10.1016/j. proci.2006.07.177.

[31] Hegner R, Werler M, Schießl R, Maas U, Atakan B. Fuel-rich HCCI engines as chemical reactors for polygeneration: a modeling and experimental study on product species and thermodynamics. Energy Fuels 2017;31(12):14079-88. https://doi.org/10.1021/acs.energyfuels.7b02150.

[32] Gossler H, Deutschmann O. Numerical optimization and reaction flow analysis of syngas production via partial oxidation of natural gas in internal combustion engines. Int J Hydrogen Energy 2015;40(34):11046-58. https://doi.org/10.1016/ j.ijhydene.2015.06.125.

[33] Cai L, Pitsch H. Optimized chemical mechanism for combustion of gasoline surrogate fuels. Combust Flame 2015;162(5):1623-37. https://doi.org/10.1016/j. combustflame.2014.11.018.

[34] Sen F, Shu B, Kasper T, Herzler J, Welz O, Fikri M, et al. Shock-tube and plug-flow reactor study of the oxidation of fuel-rich $\mathrm{CH}_{4} / \mathrm{O}_{2}$ mixtures enhanced with additives. Combust Flame 2016;169:307-20. https://doi.org/10.1016/j. combustflame.2016.03.030.

[35] Heghes CI. C1-C4 hydrocarbon oxidation mechanism. Heidelberg University Library; 2007.

[36] Hidaka Y. Shock-tube and modeling study of methane pyrolysis and oxidation. Combust Flame 1999;118(3):340-58. https://doi.org/10.1016/S0010-2180(99) 00010-3.

[37] Hoyermann K, Mauß F, Zeuch T. A detailed chemical reaction mechanism for the oxidation of hydrocarbons and its application to the analysis of benzene formation in fuel-rich premixed laminar acetylene and propene flames. Phys Chem Chem Phys 2004;6(14):3824-35. https://doi.org/10.1039/B404632C.

[38] Hidaka Y, Masaoka H, Oshita H, Nakamura T, Tanaka K, Kawano H. Thermal decomposition of vinylacetylene in shock waves. Int J Chem Kinet 1992;24(10): 871-85. https://doi.org/10.1002/kin.550241005.

[39] Hidaka Y, Nakamura T, Miyauchi A, Shiraishi T, Kawano H. Thermal decomposition of propyne and allene in shock waves. Int J Chem Kinet 1989;21(8): 643-66. https://doi.org/10.1002/kin.550210805.

[40] Pitz WJ, Naik CV, Mhaoldúin TN, Westbrook CK, Curran HJ, Orme JP, et al. Modeling and experimental investigation of methylcyclohexane ignition in a rapid compression machine. Proc Combust Inst 2007;31(1):267-75. https://doi.org/ 10.1016/j.proci.2006.08.041.

[41] Marinov NM. A detailed chemical kinetic model for high temperature ethanol oxidation. Int J Chem Kinet 1999;31(3):183-220. https://doi.org/10.1002/(SICI) 1097-4601(1999)31:3<183:AID-KIN3>3.0.CO;2-X.

[42] Echekki T, Mastorakos E. Turbulent combustion modeling. Dordrecht: Springer Netherlands; 2011.

[43] Turányi T, Tomlin AS. Analysis of kinetic reaction mechanisms. Heidelberg: Springer; 2014.

[44] Porras S, Bykov V, Gol'dshtein V, Maas U. Joint characteristic timescales and entropy production analyses for model reduction of combustion systems. Entropy 2017;19(6):264. https://doi.org/10.3390/e19060264.

[45] Bykov V, Gol'dshtein V, Maas U. Scaling invariant interpolation for singularly perturbed vector fields (SPVF). In: Gorban' AN, Roose D, editors. Coping with complexity: model reduction and data analysis. Berlin, Heidelberg: Springer; 2011. p. 91-111. 10.1007/978-3-642-14941-2_5. 978-3-642-14940-5. 
[46] Porras S, Yu C, Bykov V, Maas U. Global Quasi-Linearization (GQL) method for high dimensional detailed reaction mechanisms. In: 9th European combustion meeting, lisboa, Portugal; 2019. https://ecm2019lisbon.wixsite.com/ecm2019.

[47] Porras S, Bykov V, Gol'dshtein V, Maas U. Reduction of detailed reaction mechanisms using characteristic time scales: analysis and implementation. In: 8th European combustion meeting. Dubrovnik, Croatia; 2017. http://www.adriacom bustioninstitute.org/ecm2017/.

[48] Maas U, Warnatz J. Ignition processes in hydrogen oxygen mixtures. Combust Flame 1988;74(1):53-69. https://doi.org/10.1016/0010-2180(88)90086-7.

[49] Herzler J, Fikri M, Schulz C. High-pressure shock-tube study of the ignition and product formation of fuel-rich dimethoxymethane (DMM)/air and CH4/DMM/air mixtures. Combust Flame 2020;216:293-9. https://doi.org/10.1016/j. combustflame.2020.03.008.

[50] Kaczmarek D, Atakan B, Kasper T. The influence of pressure and equivalence ratio on the NTC behavior of methane. Proc Combust Inst 2021;38. https://doi.org/ 10.1016/j.proci.2020.06.112.

[51] Kaczmarek D, Atakan B, Kasper T. Investigation of the partial oxidation of methane/n-heptane-mixtures and the interaction of methane and n-heptane under ultra-rich conditions. Combust Flame 2019;205:345-57. https://doi.org/10.1016/ j.combustflame.2019.04.005.

[52] Kaczmarek D, Atakan B, Kasper T. Plug-flow reactor study of the partial oxidation of methane and natural gas at ultra-rich conditions. Combust Sci Technol 2019; 191:1571-84. https://doi.org/10.1080/00102202.2019.1577829.

[53] Drost S, Robert Schießl R, Maas U. Rapid compression machine (RCM) studies on the production of unsaturated hydrocarbons from methane",. In: Proceedings of the 27th international colloquium on the dynamics of explosions and reactive systems, paper 257. http://www.icders.org/ICDERS2019/abstracts/ICDERS2019-257.pdf.

[54] You X, Wang H, Goos E, Sung C-J, Klippenstein SJ. Reaction kinetics of CO + HO (2) - products: ab initio transition state theory study with master equation modeling. J Phys Chem 2007;111(19):4031-42. https://doi.org/10.1021/ jp067597a.

[55] Werler Marc R Schieß1, Robert Maas U. A rapid compression expansion machine (RCEM) for measuring species histories. Paper 0859. 2017. 2017.

[56] Atakan B. Compression-expansion processes for chemical energy storage: thermodynamic optimization for methane, ethane and hydrogen. Energies 2019;12 (17):3332. https://doi.org/10.3390/en12173332.

[57] Billaud FG, Gueret CP, Baronnet F. Thermal coupling of methane in a tubular flow reactor: experimental setup and influence of temperature. Ind Eng Chem Res 1992; 31(12):2748-53. https://doi.org/10.1021/ie00012a018.

[58] Wang S, Davidson DF, Hanson RK. Improved shock tube measurement of the CH4 $+\mathrm{Ar}=\mathrm{CH} 3+\mathrm{H}+\mathrm{Ar}$ rate constant using UV cavity-enhanced absorption spectroscopy of CH3. J Phys Chem 2016;120(28):5427-34. https://doi.org/ 10.1021/acs.jpca.6b02572.

[59] Ranzi E, Frassoldati A, Grana R, Cuoci A, Faravelli T, Kelley AP, et al. Hierarchical and comparative kinetic modeling of laminar flame speeds of hydrocarbon and oxygenated fuels. Prog Energy Combust Sci 2012;38(4):468-501. https://doi.org/ 10.1016/j.pecs.2012.03.004.

[60] Guéret C, Daroux M, Billaud F. Methane pyrolysis: thermodynamics. Chem Eng Sci 1997;52(5):815-27. https://doi.org/10.1016/S0009-2509(96)00444-7.

[61] Drost S, Schieß1 R, Maas U. Feasibility of natural gas pyrolysis for production of unsaturated hydrocarbons: an RCM study. In: 9th European combustion meeting. Lisboa, Portugal; 2019. https://ecm2019lisbon.wixsite.com/ecm2019.

[62] Nativel D, Shu B, Herzler J, Fikri M, Schulz C. Shock-tube study of methane pyrolysis in the context of energy-storage processes. Proc Combust Inst 2019;37(1): 197-204. https://doi.org/10.1016/j.proci.2018.06.083.

[63] Herzler J, Nativel D, Fikri M, Schulz C. Untersuchung des Zerfalls von Methan und Erdgas für die chemische Energiespeicherung. In: Flammentag. http://www.leat. rub.de/index.php?do=Flammentag.html.

[64] Wang H, You X, Joshi AV, Davis SG, Laskin A, Egolfopoulos F, et al. USC mech version II. High-temperature combustion reaction model of H2/CO/C1-C4 compounds. Available from: http://ignis.usc.edu/USC_Mech_II.htm.

[65] Banke K, Hegner R, Schröder D, Schulz C, Atakan B, Kaiser SA. Power and syngas production from partial oxidation of fuel-rich methane/DME mixtures in an HCCI engine. Fuel 2019;243:97-103. https://doi.org/10.1016/j.fuel.2019.01.076.

[66] Wiemann S, Hegner R, Atakan B, Schulz C, Kaiser SA. Combined production of power and syngas in an internal combustion engine - experiments and simulations in SI and HCCI mode. Fuel 2018;215:40-5. https://doi.org/10.1016/j. fuel.2017.11.002.

[67] Calise F, d'Accadia MD, Piacentino A. Exergetic and exergoeconomic analysis of a renewable polygeneration system and viability study for small isolated communities. Energy 2015;92(3):290-307. https://doi.org/10.1016/j. energy.2015.03.056. SI.

[68] Calise F, d'Accadia MD, Macaluso A, Piacentino A, Vanoli L. Exergetic and exergoeconomic analysis of a novel hybrid solar-geothermal polygeneration system producing energy and water. Energy Convers Manag 2016;115:200-20. https://doi.org/10.1016/j.enconman.2016.02.029.

[69] Foucher F, Higelin P, Mounam-Rousselle C, Dagaut P. Influence of ozone on the combustion of n-heptane in a HCCI engine. Proc Combust Inst 2013;34(2): 3005-12. https://doi.org/10.1016/j.proci.2012.05.042.

[70] Nishida H, Tachibana T. Homogeneous charge compression ignition of natural gas/ air mixture with ozone addition. J Propul Power 2006;22(1):151-7. https://doi. org/10.2514/1.14991.

[71] Masurier J-B, Foucher F, Dayma G, Dagaut P. Investigation of iso-octane combustion in a homogeneous charge compression ignition engine seeded by ozone, nitric oxide and nitrogen dioxide. Proc Combust Inst 2015;35(3):3125-32. https://doi.org/10.1016/j.proci.2014.05.060.

[72] Masurier J-B, Foucher F, Dayma G, Dagaut P. Ozone applied to the homogeneous charge compression ignition engine to control alcohol fuels combustion. Appl Energy 2015;160:566-80. https://doi.org/10.1016/j.apenergy.2015.08.004.

[73] Gossler H, Drost S, Porras S, Schießl R, Maas U, Deutschmann O. The internal combustion engine as a CO2 reformer. Combust Flame 2019;207:186-95. https:// doi.org/10.1016/j.combustflame.2019.05.031.

[74] Lazzaretto A, Tsatsaronis G. SPECO: a systematic and general methodology for calculating efficiencies and costs in thermal systems. Energy 2006;31(8-9): 1257-89. https://doi.org/10.1016/j.energy.2005.03.011.

[75] Balli O, Aras H, Hepbasli A. Exergoeconomic analysis of a combined heat and power (CHP) system. Int J Energy Res 2008;32(4):273-89. https://doi.org/ 10.1002/er.1353.

[76] Tsatsaronis G. Definitions and nomenclature in exergy analysis and exergoeconomic. Energy 2007;32(4):249-53. https://doi.org/10.1016/j. energy.2006.07.002.

[77] Tsatsaronis G. Thermoeconomic analysis and optimization of energy systems. Prog Energy Combust Sci 1993;19(3):227-57. https://doi.org/10.1016/0360-1285(93) 90016-8.

[78] Schröder D, Hegner R, Güngör A, Atakan B. Exergoeconomic analysis of an HCCI engine polygeneration process. Energy Convers Manag 2020;203:112085. https:// doi.org/10.1016/j.enconman.2019.112085.

[79] Hegner R, Atakan B. A polygeneration process concept for HCCI-engines modeling product gas purification and exergy losses. Int J Hydrogen Energy 2017; 42(2):1287-97. https://doi.org/10.1016/j.ijhydene.2016.09.050.

[80] Sala JM, López-González LM, Ruiz de Adana M, Míguez JL, Eguía J, Flores I. Exergetic analysis and thermoeconomic study for a container-housed engine. Appl Therm Eng 2006;26(16):1840-50. https://doi.org/10.1016/j. applthermaleng.2006.02.005.

[81] Keipi T, Tolvanen H, Konttinen J. Economic analysis of hydrogen production by methane thermal decomposition: comparison to competing technologies. Energy Convers Manag 2018;159:264-73. https://doi.org/10.1016/j. enconman.2017.12.063.

[82] Schröder D, Hegner R, Güngör A, Atakan B. The influence of uncertainty of economic parameters and upscaling on product costs of an engine polygeneration system. In: Proceedings of the 32nd international conference on efficiency, cost, optimization, simulation and environmental impact of energy systems. ECOS 2019. Wrocław, Poland; 2019. https://www.buildup.eu/en/events/ecos-2019-32nd-inte rnational-conference-efficiency-cost-optimization-simulation-and.

[83] Saltelli A, Ratto M, Andres T, Campolongo F, Cariboni J, Gatelli D, et al. Global sensitivity analysis: the primer. Chichester: Wiley; 2008.

[84] Peters MS, Timmerhaus KD, West RE. Plant design and economics for chemical engineers. fifth ed. Boston: McGraw-Hill; 2004.

[85] Schröder D, Banke K, Kaiser SA, Atakan B. The kinetics of methane ignition in fuelrich HCCI engines: DME replacement by ozone. In: Proc. Combust. Inst., vol. 38; 2021. 